\title{
Cost-effective Strategy for Heat Exchanger Network Retrofit
}

DOI:

10.1016/j.energy.2017.09.005

\section{Document Version}

Accepted author manuscript

Link to publication record in Manchester Research Explorer

\section{Citation for published version (APA):}

Akpomiemie, M., \& Smith, R. (2017). Cost-effective Strategy for Heat Exchanger Network Retrofit. Energy. https://doi.org/10.1016/j.energy.2017.09.005

\section{Published in:}

Energy

\section{Citing this paper}

Please note that where the full-text provided on Manchester Research Explorer is the Author Accepted Manuscript or Proof version this may differ from the final Published version. If citing, it is advised that you check and use the publisher's definitive version.

\section{General rights}

Copyright and moral rights for the publications made accessible in the Research Explorer are retained by the authors and/or other copyright owners and it is a condition of accessing publications that users recognise and abide by the legal requirements associated with these rights.

\section{Takedown policy}

If you believe that this document breaches copyright please refer to the University of Manchester's Takedown Procedures [http://man.ac.uk/04Y6Bo] or contact uml.scholarlycommunications@manchester.ac.uk providing relevant details, so we can investigate your claim.

\section{OPEN ACCESS}



Science, The University of Manchester, Manchester, M13 9PL, UK. *Corresponding authors' email address: mary.akpomiemie@processint.com

Abstract

9 Cost-effective retrofit of heat exchanger networks (HENs) remains a significant 10 challenge. This paper explores different methods for achieving cost-effective retrofit.

11 The first part of this article presents a novel methodology for the application of heat transfer enhancement in HEN retrofit with a fixed network structure considering

13 pressure drop constraints. Heat transfer enhancement is a low-cost option. However, 14 heat transfer enhancement on its own without changes to the network structure 15 provides a limited scope for energy reduction. The second part of this paper presents a 16 new pinch retrofit method that identifies network structural changes sequentially to meet the retrofit target. However, the high capital cost associated with installing new 18 heat exchangers, relocating existing exchangers, and augmenting the heat transfer area 19 of existing heat exchangers most often leads to uneconomic retrofits. Low-cost retrofit 20 requires few modifications. Therefore, the third part of this paper combines the new 21 pinch retrofit method with the use of heat transfer enhancement to provide low-cost 22 retrofit by combining the merits of both approaches. A case study highlights the 23 benefits of the new approach. 
25 Keywords: Heat exchanger network; Retrofit; Heat transfer enhancement; Structural Modifications; Pinch retrofit method; Pressure drop

\section{Introduction}

Increasing concerns associated with greenhouse gas emissions have led to a rise in interest into the retrofit of heat exchanger networks (HENs). In the process industries, the retrofit of HENs can be a cost-effective method to reduce the energy consumption. Maximising the use of existing equipment increases the profitability of the retrofit process [1]. In existing HENs, operating and physical constraints referred to as bottlenecks restrict the degree of energy savings.

Established techniques and methodologies for the retrofit of HENs focus on modifying the existing HENs to obtain energy savings and overcome network bottlenecks. Modifications to the existing HEN are primarily based on Pinch Analysis, Mathematical Programming, and Hybrid methods. There are several reports in literature dedicated to the retrofit of HENs based on these methods. Sreepathi and Rangaiah [2] presented a detailed review of the different methods for HEN retrofit. The book by Smith [3] has full chapters that introduce the fundamentals of energy targets, capital and total cost targets, and network design of HENs. Pinch Analysis for retrofit makes use of a targeting stage for estimating the maximum energy recovery of a network, and a re-design stage to disconnect and reconnect the cross-pinch exchangers to obey the pinch decomposition. The pioneering work on Pinch Analysis for retrofit was introduced by Tjoe and Linnhoff [4]. The objective of the work is to eliminate heat transfer across the pinch. This concept has since been extended to account for the cost required in HEN retrofit [5]. Most recently, the work by Gadalla [6] presented a new graphical method based on Pinch Analysis. The energy efficiency 
50 is evaluated quantitatively in the existing HEN to identify the potential modifications

51 for better energy recovery. The drawbacks of Pinch Analysis are that it requires an

52 expert user for its application and does not highlight the number of modifications

53 required and the appropriate placement for the additional heat transfer area

54 requirement. Also, Pinch Analysis requires too many changes in a single step, which

55 makes it fundamentally not suited to retrofit, as it tries to convert the existing network

56 into an ideal grass root design in a single step instead of accepting the features that

57 already exist.

58 Mathematical programming methods convert the retrofit problem into an optimisation

59 model and solved. However, the HEN retrofit is a mixed integer non-linear

60 programming (MINLP) problem [7]. Ciric and Floudas [8] presented a superstructure

61 approach for retrofit of HENs. The objective of the approach is to optimise the

62 superstructure which contains all structural features of an existing HEN to remove all

63 unnecessary features and minimise the cost. The difficulty in solving the MINLP

64 problem has led to authors simplifying the retrofit problem to avoid obtaining a local

65 optimum solution. Over the years, several authors developed ways of decomposing

66 the retrofit problem. Ma et al. [9] developed the Constant Approach Temperature

67 model used to linearise the area calculations. Other authors [10] presented a two-stage

68 approach to retrofit. The first stage, the prescreening stage is solved as a mixed

69 integer linear programming (MILP) problem. The second stage, the optimisation stage

70 is solved as a nonlinear programming (NLP) problem. Another way to overcome the

71 difficulty in solving the MINLP problem might be to apply stochastic optimisation

72 [11]. A benefit of mathematical programming methods is that the total cost and

73 environment impact of retrofit can be considered in the optimisation process [12].

74 Compared to the Pinch Analysis method, mathematical programming methods can 
consider more variables and identify the optimal HEN. In general, the drawbacks associated with the use of mathematical programming techniques include prolonged computational times, uncertainty in the optimality of the solution due to the assumptions and simplifications made to the model and the lack of user interaction.

Asante and Zhu [13] pioneered the hybrid method for the retrofit of HENs. The method proposed, referred to as the Network Pinch Approach, consists of a diagnosis and an optimisation stage. In the diagnosis stage, the MILP model is used to identify the possible structural modifications that can provide maximum energy recovery subject to an assumed minimum temperature approach. The optimisation stage makes use of an NLP model to optimise the capital-energy trade-off of the structural modifications determined in the first stage. The sequential approach enables the automation of the design procedure while maintaining user interaction. Smith et al. [14] modified the Network Pinch Approach by converting the process from sequential to simultaneous (considering structural modifications and capital-energy optimisation in a single step). The Network Pinch Approach by Asante and Zhu [13] was later extended to handle more complex networks considering some practical features to increase the possibility of identifying cost-effective design solutions [15]. The Network Pinch Approach provides energy savings by manipulating the existing degrees of freedom (utility paths, loops and stream splits) in an existing network [3]. However, the only way of overcoming the Network Pinch for energy savings is by performing structural modifications. Examples of modifications considered to overcome the Network Pinch are adding a new heat exchanger (new match), relocating exchangers (resequencing), adding stream splits. The Network Pinch Approach is an automated sequential method restricted to one change at a time. The drawback with the Network Pinch Approach is the lack of insights into the decision- 
making process of identifying the best series of modifications that can be applied to a

101 given HEN. As such, there is a possibility of selecting a retrofit option early in the

102 procedure that prevents obtaining the optimal solution in subsequent steps.

103 In recent years, there has been a rise in the research into the use of heat transfer

104 enhancement in retrofit. Heat transfer enhancement not only increases energy

105 recovery but can be a low-cost option for retrofit as existing network structure can be

106 maintained. This makes the implementation of enhancement devices relatively simple

107 and can be performed during the normal shutdown period. Optimisation methods

108 presented by Pan et al. [16] applied detailed models of different heat transfer

109 enhancement techniques for the application of heat transfer enhancement. The authors

110 also provided a systematic design method for the application of conventional retrofit

111 strategies [17]. Optimisation methods provide no insights into the identification of the

112 best heat exchangers to enhance. Also, the simplifications in the retrofit method lead

113 to uncertainty in the retrofit solution. Heuristic based methods have been developed to

114 tackle the issues presented by optimisation methods for the application of heat transfer

115 enhancement. Wang et al. [18] presented a method based on sensitivity analysis.

116 However, this approach did not consider the impact of enhancement on the network.

117 Also, the degree of enhancement is assumed. Jiang et al. [19] extended the approach

118 to consider accurate modelling of the chosen enhancement technique to ensure

119 accurate representation of proposed energy savings. The work by Akpomiemie and

120 Smith [20] extended both methodologies to account for the downstream effects on the

121 network after the application of heat transfer enhancement. The drawbacks with the

122 use of sensitivity analysis for identifying the best heat exchanger to enhance were

123 highlighted by Akpomiemie and Smith [21]. The authors [21] presented an alternative

124 method known as the area ratio approach for the identification of the best heat 
125 exchangers to enhance. With this method, the decision on the best heat exchanger is 126 not dependent on a key utility exchanger, as in the case of sensitivity analysis, but on 127 the degree of enhancement that a heat exchanger can provide relative to its base case 128 value. As such, this method is more suited to HENs with multiple utilities. A 129 drawback of the heuristic based methods considering enhancement is the lack of 130 pressure drop considerations with heat transfer enhancement. Ignoring the effects of 131 pressure drop in retrofit might present a retrofit result that cannot be realised 132 industrially as the existing pumps/compressors might not be able to cope with the 133 increased pressure drop requirements.

134 Polley et al. [22] first considered the effects of pressure drop in retrofit. However, the 135 work only considers a targeting stage based on area efficiency and does not present a 136 systematic way of applying heat transfer enhancement in retrofit. Nie and Zhu [23] 137 presented practical methods for mitigating the effects of pressure drop in a network 138 after structural modifications are made. Techniques considered include decreasing the 139 number of tube passes and modifying shell arrangements from series to parallel. Both 140 methods have an impact on the tube-side velocity of the exchangers, which dictates 141 not only the heat transfer coefficient but also the pressure drop requirement.

142 Recent methods used for the retrofit of HENs with pressure drop considerations have 143 either been based on an iterative MILP optimisation approach [24] or a combination 144 of a set of heuristic rules and NLP optimisation [25]. The drawbacks of the MILP 145 optimisation approach are that there is a lack of insights into identifying the best 146 exchangers to enhance and the use of the MILP model to solve the retrofit problem.

147 To address these drawbacks, the work by Akpomiemie and Smith [25] present a novel 148 sequential approach to retrofit with heat transfer enhancement considering pressure 149 drop constraints. The new approach provides insights into identifying the best 
exchangers to enhance. The new method also defines a ranking criterion for selecting

151 the best pressure drop mitigation technique. An NLP model is used to ensure the

152 feasibility of the retrofit solution based on a set of constraints. However, the energy

153 savings that can be obtained for fixed network structure with heat transfer

154 enhancement is limited [26]. To obtain high energy recovery, structural modifications

155 to the existing HEN are required.

156 From the reviewed methods for performing structural modifications, the Network

157 Pinch Approach presents the right balance between providing optimal solutions and

158 user interaction. Studies based on the Network Pinch approach [14, 15] do not provide

159 insights into the decision-making process for selecting the best series of structural

160 modifications in retrofit. To overcome this drawback, this work presents a new pinch

161 retrofit method that provides insights into the fundamental interactions and features of

162 an existing HEN. The Network Pinch Approach identifies the bottleneck for heat

163 recovery in an existing system. However, it provides no guidance as to how to

164 overcome the Network Pinch. Overcoming Network Pinch is left to the use of NLP

165 optimisation. This provides no insights into the solution and no insights as to whether

166 other options might provide an equivalent answer. User intervention is particularly

167 important in industrial retrofit. The problem is not the purchase of new equipment, but

168 the many other issues of pipework and civil engineering requirements and in many

169 situations simply the ability to accommodate new equipment. These issues cannot be

170 included in optimisation, but require user insights. The paper presents an approach

171 that allows the designer to include insights into the decision-making.

172 The main objective of this work focuses on providing low-cost retrofit methods for

173 HENs. This work presents the benefits of combining the use of heat transfer

174 enhancement and structural changes to existing HENs. The new method is applied 
sequentially with an objective of maximising energy recovery with minimum

176 investment. A case study is used to illustrate the proposed methods and highlight their

177 benefits by making a comparative analysis of the various options considered in this

178 work for HEN retrofit.

\section{Heat Transfer Enhancement for a Fixed Network Structure}

180 This section of the paper summarises the method presented by Akpomiemie and

181 Smith [25] for the application of heat transfer enhancement for a fixed network

182 structure with pressure drop considerations. The approach combines a set of heuristic

183 rules and optimisation to meet the retrofit target. Figure 1 shows the retrofit 184 methodology. Initially, the retrofit profit (RP) is 0.

$185 \quad 2.1 \quad$ Heuristic 1: Identify the best heat exchanger for enhancement

186 The two-step approach presented by Akpomiemie and Smith [20, 21] is used to

187 determine the best sequence of enhanced exchangers.

$188 \quad 2.1 .1$ Step 1: Identify exchangers on a utility path

189 A way of reducing the energy consumption in an existing HEN while maintaining the

190 network structure is by shifting heat loads along a utility path. A utility path is a

191 connection between two utilities through process exchangers. Therefore, for the

192 application of heat transfer enhancement for a fixed network structure, only

193 exchangers on a utility path are considered. For simple networks, heat exchangers on

194 a utility path can be identified by inspection. However, for complex heat exchanger

195 networks, the use of inspection is not reliable as key exchangers on a utility path in

196 the network might be missed. Therefore, in the first step, a more systematic method,

197 the Incidence Matrix Approach [26] is proposed. The identification of utility paths 
198 based on the Incidence Matrix Approach is split into three steps, i.e. generation of the 199 initial matrix, reducing the matrix, and utility path identification by linear 200 combination.

\subsubsection{Incidence matrix generation}

202 The Incidence Matrix Approach is based on the fundamentals of graph theory for 203 process modelling. A graph contains a set of nodes and edges. The Incidence Matrix 204 depicts the relationship between the set of nodes and the corresponding edges, i.e. 205 describes how the edges are incident on nodes [27]. The rows represent the nodes, and 206 the columns represent the edges. In relation to HENs, the nodes are considered to be 207 all streams in the network and the columns represent exchangers. The number of 208 streams is denoted by $S$ and the number of exchangers by $E$ in this work. The 209 Incidence Matrix $\mathrm{A}_{\mathrm{HEN}}$ (size $S \times E$ ) describes how the streams are incident on 210 exchangers. The rows represent streams, and the columns represent exchangers.

$$
\mathrm{A}_{\mathrm{HEN}(i k)}=\left\{\begin{array}{cl}
+1 & \text { if exchanger } \mathrm{k} \text { removes heat from stream i } \\
-1 & \text { if exchanger } \mathrm{k} \text { supplies heat to stream } \mathrm{i} \\
0 & \text { if exchanger } \mathrm{k} \text { is not incident on stream } \mathrm{i}
\end{array}\right.
$$

211 Each column of $A_{H E N}$ will have exactly two non-zero entries, i.e. one +1 and one -1

212 entry. This is because a heat exchanger can only be matched between two streams.

213 However, the difference between the new methodology based on Incidence Matrix 214 and the standard Incidence Matrix is the addition of a column vector $P$ to the matrix.

215 The column vector $P$ serves as a connection between two utilities, i.e. a utility path.

216 As such, in the Incidence Matrix generated, a value of +1 is added to the hot utility

217 stream and -1 to the cold utility stream. Explanation on how the column vector $P$ is 218 used in identifying exchangers on a utility path is provided in Section 2.1.1.3 of this 219 paper. 
220 Figure 2 shows an example network that will be used to generate the Incidence

221 Matrix. Table 1 shows the Incidence Matrix for the example network. For example, 222 Exchanger 1 removes heat from stream 3 and supplies heat to stream 5. Therefore, in 223 Table 1, a value of +1 and -1 has been added in Column 1 (representing Exchanger 1). 224 The procedure is repeated for all other process and utility exchangers in the network. 225 From Table 1, it can also be noted that the column vector $P$ is added to the Incidence 226 Matrix. A value of +1 is added to signify the hot utility stream (HU) and -1 to signify 227 the cold utility stream (CU).

228 2.1.1.2 Reducing the initial incidence matrix

229 As stated earlier, the column vector $P$ signifies the link between two utilities and by 230 definition, the utility path. However, the column vector $P$ is given by a linear 231 combination of the reduced Incidence Matrix. Therefore, the initial Incidence Matrix 232 is reduced by performing row operations. This is to ensure that all entries below the 233 first non-zero entry of each row in the matrix are zero.

234 From Table 1, the first non-zero entry in Row 1 is in Column 3. Column 3 is analysed 235 to identify the non-zero entry below the first entry. From Table 1, the first non-zero 236 entry is found in Row 4. Row 1 is added to Row 4 to eliminate this entry. Repeat the 237 procedure for all other entries in the initial Incidence Matrix. Table 2 shows the 238 reduced matrix. From Table 2 it can be noted that all entries below the first non-zero 239 entry of each row are now zero and the matrix has been reduced. Row CU now only 240 has zero entries.

241 2.1.1.3 Utility path identification by linear combination

242 Linear combination is performed based on an important feature of utility paths. Utility 243 paths allow for heat loads to be shifted from one unit to another. The amount of heat 244 load added to a heater must be subtracted from an exchanger in the path, added to the 
next exchanger in the path, and so on, and finally added to a cooler in the path.This operation maintains the enthalpy balance and target temperatures of streams in the HEN.

In relation to the Incidence Matrix approach, the column profile identified by

249 performing the plus-minus analysis must be equal to the column vector $\mathrm{P}$ i.e.

Therefore, Column $\mathrm{X}_{\mathrm{k}=1 \rightarrow \mathrm{N}}=$ Column $\mathrm{P}-$ Column $\mathrm{H}_{\mathrm{k}=1 \rightarrow \mathrm{N}}-$ Column $\mathrm{C}_{\mathrm{k}=1 \rightarrow \mathrm{N}}$

252 Where the column profile of Column $X_{k}=1 \rightarrow N$ is obtained by performing random 253 combinations of the columns in the reduced matrix except for the utility columns 254 (Column $H_{k=1 \rightarrow N}$ and Column $C_{k=1 \rightarrow N}$ ). Note that $X_{k=1 \rightarrow N}$ can only be one column, 255 representing one exchanger or a combination of an odd number of columns, i.e. 3, 5, 2567 , etc. Also, the plus-minus rule applies when $X$ is a representation of a combination 257 of columns. This procedure has been automated as part of a Centre for Process 258 Integration software, SPRINT [28]. For example, if three columns are considered, $X$ 259 will be obtained from performing $C 1-C 2+C 3$ or a different combination of the 260 three columns. For the example discussed here, the utility paths are given in Figures 3 261 and 4.

\subsubsection{Step 2: Determine the rank of identified exchangers}

263 The second step involves evaluating the energy saving potential of candidate heat 264 exchangers, i.e. exchangers on a utility path. For this, either sensitivity analysis [18, 265 19, and 20] or area ratio approach [21] can be used. Sensitivity analysis is based on 266 the well-known heat transfer equation: 
268 Where $\mathrm{Q}, \mathrm{U}, \mathrm{A}, \Delta \mathrm{T}_{\mathrm{LM}}, \mathrm{F}_{\mathrm{T}}$ are the heat duty, overall heat transfer coefficient, heat 269 transfer area, logarithmic mean temperature difference and correction factor 270 respectively. Sensitivity analysis is carried out by varying the product of the overall 271 heat transfer coefficient, heat transfer area and correction factor against the inlet 272 temperature of a key utility exchanger. This key utility exchanger is usually the most 273 expensive utility. With sensitivity analysis, the best heat exchanger to enhance is one 274 which brings about the greatest increase in the inlet temperature of the key utility 275 exchanger. This identifies a heat exchanger that can provide the greatest decrease in 276 the energy consumption of this key utility exchanger in order not to violate the target 277 temperature of the stream on which it is located. The work by Wang et al. [18] 278 identified reasons for high sensitivity in particular heat exchangers such as their 279 proximity to the key utility, the heat capacity flowrate and the minimum temperature 280 difference of the candidate heat exchangers. The benefit of sensitivity analysis is that 281 it provides simple insights into the existing network. However, the decision is based 282 on an unbalanced network. Also, its dependence on a key utility exchanger makes it 283 difficult to be applied to networks with multiple utilities [21]. Therefore, Akpomiemie 284 and Smith [21] presented a new method for identifying the best exchangers to 285 enhance, i.e. the area ratio approach, where the area ratio is determined by Equation 2

$$
\mathrm{A}_{\mathrm{R}}=\frac{\mathrm{A}}{(\mathrm{A}+\Delta \mathrm{A})}=\frac{\mathrm{U}}{\mathrm{U}_{\mathrm{E}}} \quad \text { Equation } 2
$$

286 Based on this equation, the best heat exchanger to enhance is one with the smallest 287 area ratio as this signifies the heat exchanger that can provide the greatest degree of 288 enhancement relative to its base case value. The benefit of this method is that the best 289 heat exchanger is identified based on the maximum allowable enhancement of each 290 candidate heat exchanger that still maintains a balanced network. This makes it more 
291 suited to networks with multiple utilities as the decision is not dependent on a key

292 utility exchanger as in the case of sensitivity analysis.

293

294

295

296

297

\subsection{Heuristic 2: Apply enhancement}

The best exchanger for enhancement identified from Heuristic 1 is enhanced first. For a shell and tube heat exchanger, the decision on where to apply enhancement is based on the side with the highest percentage resistance, i.e. the side with the lower heat transfer coefficient. Jiang et al. [29] presented new models for heat exchangers enhanced with tube inserts for heat exchangers in retrofit. This model is used in our work to determine the maximum degree of enhancement for each candidate exchanger based on their geometry.

\subsection{Heuristics 3 and 3.1: Check for stream pressure drop violation and identi- fy the best pressure drop mitigation technique and apply.}

Most enhancement devices have an adverse effect on pressure drop. In retrofit, replacing existing compressors/pumps to cope with the increase in pressure drop requirements might not be economic. In an existing HEN, maximum allowable pressure drop constrains each stream. Therefore, after each enhancement, the stream pressure drop should be checked for any violations, and if there are, corrected using pressure drop mitigation techniques (Heuristic 3.1). If not continue to Step 4 in the retrofit methodology. The decision on what technique to apply depends on the stream that is constrained. For example, if the shell side is constrained, helical baffles or changing the shell arrangements could be considered. If on the other hand, the constraint is on the tube side, a reduction in the number of tube passes or change in the shell arrangement could be considered. This work focuses on tube side enhancement, and as such, only mitigation techniques that can be applied to the tube side are discussed. Reducing the number of tube passes decreases the tube-side 
316 velocity and as such, the pressure drop. However, the performance of the heat 317 exchanger will also be affected, but performance can still be improved with 318 enhancement but at a lower pressure drop penalty. The presence of more than one 319 shell in a heat exchanger offers an opportunity for pressure drop mitigation. The total 320 pressure drop of the heat exchanger is dependent on the shell arrangement. Different 321 shell arrangements have different impacts on pressure drop. To reduce the pressure 322 drop requirements, shells in series can be arranged in parallel. By doing so, the total 323 pressure drop is no longer a sum of the pressure drop of each shell but the maximum 324 pressure drop in either of the shells. With a parallel arrangement, the heat transfer 325 coefficient and pressure drop are lower as the flow going through each shell is lower 326 than that of series arrangement. Similar to modifying the number of tube passes, the 327 performance can still be increased with enhancement but at a lower pressure drop 328 penalty. Figure 5 shows the different shell arrangements that can be applied to a heat 329 exchanger depending on the number of shells present. Equations for determining to 330 total pressure drop in each scenario is provided.

331 For a given heat exchanger, there might be more than one mitigation technique that 332 can be applied. Therefore, a ranking criterion is required. The work by Akpomiemie 333 and Smith [26] defines the selection factor (SF) as the relationship between the 334 change in pressure drop relative to the change in the degree of enhancement before 335 and after applying modifications (see Equation 3). The best option is one with the 336 smallest SF, as this signifies the modification that can still provide a higher degree of 337 enhancement with the lowest pressure drop penalty.

$$
\mathrm{SF}=\left(\frac{\Delta \mathrm{P}_{\mathrm{N}, \mathrm{E}}-\Delta \mathrm{P}_{\mathrm{N}, \mathrm{ex}}}{\Delta \mathrm{P}_{\mathrm{B}, \mathrm{E}}-\Delta \mathrm{P}_{\mathrm{B}, \mathrm{ex}}}\right)\left(\frac{\mathrm{U}_{\mathrm{B}, \mathrm{E}}-\mathrm{U}_{\mathrm{B}}}{\mathrm{U}_{\mathrm{N}, \mathrm{E}}-\mathrm{U}_{\mathrm{N}}}\right) \quad \text { Equation 3 }
$$




\subsection{Heuristic 4 and Optimisation 1: Check for target temperature and addi- tional heat transfer area violations and correct using non-linear optimisa- tion model}

The next step in the retrofit methodology is to check for stream target temperature and heat transfer area violations. The target temperature violation is as a result of the increase in the duty of the enhanced heat exchanger. This violation can easily be solved using the utility exchangers on the utility path as the enhanced exchanger. The heat transfer area violation is as a result of the decrease in the driving force of heat exchangers located downstream from the enhanced heat exchanger. Shifting a certain amount of heat load along the utility path corrects the additional heat transfer area requirement. By doing this, there is a trade-off between energy recovery and capital cost (i.e. cost of additional heat transfer area) as a certain amount of heat load needs to be added back to the utility exchangers and subtracted from the heat exchanger requiring additional area. However, if the exchanger requiring additional area is not on a utility path, heat transfer enhancement can still be exploited to reduce or eliminate the heat transfer area required. This is because a benefit of heat transfer enhancement is that an enhanced heat exchanger has a higher heat transfer coefficient to exchange the same duty under smaller heat transfer area requirement. Therefore, these exchangers can be enhanced at constant duty to eliminate the heat transfer area required. To find the amount of heat load that should be shifted along the utility path and the degree of enhancement that should be applied the non-linear optimisation model proposed by Akpomiemie and Smith [20, 21] is used. However, the model presented has been extended to consider the cost associated with the application of pressure drop mitigation techniques. The objective function is to maximise the retrofit profit (RP) where: 


$$
\mathrm{RP}=\mathrm{UC}_{\mathrm{B}^{-}}\left[\mathrm{UC}_{\mathrm{E}^{+}}+\sum_{\mathrm{ex} \in \mathrm{EX}} \mathrm{RC}_{\mathrm{ex}}\right]
$$

Equation 4

363 The retrofit cost $(\mathrm{RC})$ includes the cost of all modifications and is given by:

$$
\mathrm{RC}_{\mathrm{ex}}=\mathrm{EC}_{\mathrm{ex}}+\mathrm{AC}_{\mathrm{ex}}+\mathrm{BC}_{\mathrm{ex}}+\mathrm{MC}_{\mathrm{ex}} \quad \forall_{\mathrm{ex}} \in \mathrm{EX} \quad \text { Equation } 5
$$

364 Where $\mathrm{EC}_{\mathrm{ex}}$ is the cost of enhancement, $\mathrm{AC}_{\mathrm{ex}}$ is the additional area cost, $\mathrm{BC}_{\mathrm{ex}}$ is the 365 cost of bypass, and $\mathrm{MC}_{\mathrm{ex}}$ is the mitigation cost. Equations 6 and 7 are used in 366 calculating the utility cost before $\left(\mathrm{UC}_{\mathrm{B}}\right)$ and after enhancement $\left(\mathrm{UC}_{\mathrm{E}}\right)$ where $\mathrm{CCU}$ and 367 CHU are the yearly cost parameter for cold and hot utility, $\mathrm{Q}_{\mathrm{B}}$ and $\mathrm{Q}_{\mathrm{E}}$ are the duty 368 before and after enhancement and OT is the payback operating time.

$$
\begin{array}{ll}
\mathrm{UC}_{\mathrm{B}}=\mathrm{OT} \times\left[\mathrm{CCU} \times \sum_{\mathrm{ex} \in \mathrm{EX}_{\mathrm{CU}}} \mathrm{Q}_{\mathrm{B}, \mathrm{ex}}+\mathrm{CHU} \times \sum_{\mathrm{ex} \in \mathrm{EX}_{\mathrm{HU}}} \mathrm{Q}_{\mathrm{B}, \mathrm{ex}}\right] & \text { Equation 6 } \\
\mathrm{UC}_{\mathrm{E}}=\mathrm{OT} \times\left[\mathrm{CCU} \times \sum_{\mathrm{ex} \in \mathrm{EX}_{\mathrm{CU}}} \mathrm{Q}_{\mathrm{E}, \mathrm{ex}}+\mathrm{CHU} \times \sum_{\text {ex } \in \mathrm{EX}_{\mathrm{HU}}} \mathrm{Q}_{\mathrm{E}, \mathrm{ex}}\right. & \text { Equation 7 }
\end{array}
$$

369 The aim of the optimisation model is to be able to apply heat transfer enhancement

370 without the need for additional heat transfer area while maintaining the target

371 temperatures of all streams. Equations 8 to 10 represent the constraints for heat

372 transfer area requirements and temperature constraints for all cold and hot streams, CS

373 and $\mathrm{HS}$. $\mathrm{A}_{\mathrm{ex}}$ and $\mathrm{A}_{\mathrm{E}}$ represent the heat transfer area of all process heat exchangers

374 before and after enhancement. TCOS and THOS represent the cold and hot outlet

375 stream temperatures respectively. $\mathrm{EX}_{\mathrm{E}}$ describes the set of all exchangers.

$$
\begin{array}{lll}
\mathrm{A}_{\mathrm{ex}}=\mathrm{A}_{\mathrm{E}} & \forall_{\mathrm{ex}} \in \mathrm{EX}_{\mathrm{E}} & \text { Equation 8 } \\
\mathrm{TCOS}_{\mathrm{i}}=\mathrm{TCOS}_{\mathrm{E}} & \forall_{\mathrm{CS}} & \text { Equation 9 } \\
\mathrm{THOS}_{\mathrm{i}}=\mathrm{THOS}_{\mathrm{E}} & \forall_{\mathrm{HS}} & \text { Equation 10 }
\end{array}
$$


Variables used in this model are the overall heat transfer coefficient of all process heat exchangers, subject to this value not exceeding the maximum determined based on the exchanger geometry. The duty of all heat exchangers on a utility path is another variable used in this model. It is important to point out that although the overall heat transfer coefficients of heat exchangers not on a utility path are varied, the heat exchanger duty is fixed. After correcting the violations continue to Heuristic 5.

\subsection{Heuristic 5: Check for stopping criterion violation}

Given that the retrofit objective is to maximise the retrofit profit, after the application of the non-linear optimisation model, if the retrofit profit before enhancement is greater than that after, the procedure is stopped. This means that the cost of retrofit outweighs the profit from energy savings. As such, it is uneconomic. If the stopping criterion is not violated, continue to Heuristic 6.

\subsection{Heuristic 6: Check for further retrofit options}

Given that the retrofit methodology is sequential, there might be more than one heat exchanger that can improve energy recovery. Therefore Heuristics 1 to 5 of the retrofit methodology is repeated until all potential for energy recovery has been explored. The retrofit methodology is terminated when all options have been explored, or the stopping criterion is violated.

In summary, heuristic rules are first applied to identify the best exchangers for enhancement. The maximum degree of enhancement for a selected exchanger is restricted by the geometry of the exchanger and is determined before optimisation based on the chosen enhancement technique. Optimisation is used to maintain the energy balance of the network and ensure there is no additional heat transfer area required. The energy savings that can be obtained with enhancement is restricted by 
400 the degree of enhancement that can be applied subject to no additional area 401 requirement and pressure drop constraints. The non-linear optimisation employed has 402 a $100 \%$ convergence rate.

\section{Structural Modifications (The Pinch Retrofit Method)}

404 The pinch retrofit method is based on the Network Pinch Approach presented by

405 Smith et al. [14]. However, the primary purpose of the pinch retrofit method is to 406 present guidelines for identifying the best location to apply a series of modifications 407 based on fundamental insights in a step-by-step approach from the existing network. 408 The aim is to identify the best series of modifications that can achieve maximum 409 energy recovery with the minimum number of modifications to the existing network. 410 The modifications considered in this work are resequencing, stream splitting, adding a 411 new exchanger to create a loop and adding a new exchanger to create a path.

412 Figure 6 shows the background of the pinch retrofit method. The retrofit target is 413 subject to a selected temperature driving force $\left(\Delta \mathrm{T}_{\min }\right)$ value. The $\Delta \mathrm{T}_{\min }$ value used for 414 retrofit is selected by targeting using Pinch Analysis. With an objective of obtaining a 415 cost-effective retrofit design, the effect of varying $\Delta \mathrm{T}_{\min }$ is analysed against the utility 416 consumption and costs of each value of $\Delta \mathrm{T}_{\min }$. The $\Delta \mathrm{T}_{\min }$ representing the best capital417 energy trade-off is selected. For a selected $\Delta \mathrm{T}_{\min }$, the first step is to pinch the original 418 network by manipulating the existing degrees of freedom (i.e. stream splits, utility 419 paths or loops). By doing this, the exchanger that constrains energy recovery is 420 identified. This exchanger is referred to as the pinching match, and the location at 421 which it occurs is referred to as the Network Pinch. The only way to overcome the 422 Network Pinch is by performing structural modifications. With each structural 423 modification, the temperature constraint on the pinching match is relaxed. The 
network is pinched again for energy recovery and the process repeated until the

425 Maximum Energy Recovery (MER) design is achieved for the specified $\Delta \mathrm{T}_{\min }$ in 426 retrofit.

427 To summarise, the pinch retrofit method evolves from the existing design. The 428 Network Pinch constrains each structural change. The difference between the maximum energy recovery for a given temperature driving force and the existing energy consumption is the penalty associated with cross-pinch heat transfer. The 431 cross-pinch heat transfer can be the inappropriate use of utilities (i.e., use of cold 432 utility above the pinch or hot utility below the pinch) or process-to-process 433 exchangers transferring heat across the process pinch. Therefore, the ultimate 434 constraint to achieving maximum energy recovery is to eliminate all cross-pinch heat 435 transfer in the network, but this might well be uneconomic.

436 Different networks have different features. The key features present in an existing 437 network that govern the identification of the best structural modification are pinched 438 exchangers and cross-pinch exchangers (either process-to-process or inappropriate use 439 of utilities). The location of these features in the network and their proximity to other 440 process exchangers and to one another also plays an important role in determining the 441 best modification that should be applied to the network for energy recovery.

442 Guidelines and an algorithm have been developed for structural modifications based 443 on the different network features and can be found in the work by Akpomiemie [30].

444 From the algorithm [30], before performing structural modifications, it is always 445 advisable to pinch the HEN. Pinching the HEN not only provides a degree of energy 446 saving while maintaining the network structure but also identifies the Network Pinch 447 that restricts energy recovery. Heat exchangers that contribute to heat transfer across 448 the pinch are also identified. However, this comes at an additional heat transfer area 
penalty. Outlined below are the definitions of key terms used in the guidelines for the

450 pinch retrofit method. Figure 7 shows a simple illustration of a HEN with the key

451 terms highlighted.

452 Upstream exchanger: This refers to a heat exchanger located before the reference 453 exchanger in the direction of the stream. For example, from Figure 7, selecting the 454 pinched Exchanger 2 as the reference exchanger, Exchangers 1 and 4 are located 455 upstream from the pinched exchanger on the hot and cold streams 1 and 5 456 respectively.

457 Downstream exchanger: This refers to a heat exchanger located after the reference 458 exchanger in the direction of the stream. For example, from Figure 7, selecting the 459 pinched Exchanger 2 as the reference exchanger, Exchanger 3 is located downstream 460 from the pinched exchanger on the cold stream 5.

461 The exit of heat exchangers: This refers to the outlet of a heat exchanger on the 462 streams which it is matched. For example, from Figure 7, the exits of Exchanger 3 on 463 the hot and cold streams are highlighted.

\section{Guidelines for modifications:}

466 The decision on what modifications will be the most beneficial is dependent on the 467 location of unconstrained (i.e. process exchanger with a $\Delta \mathrm{T}$ greater than $\Delta \mathrm{T}_{\min }$ of the 468 network) upstream process exchangers relative to pinched exchangers in the network. 469 In the first scenario, if there are upstream process exchangers from all pinched 470 exchangers on either the hot or cold stream which the pinched exchangers are 471 matched, resequencing or adding a new exchanger to create a loop will be the most 472 beneficial options. The difference between adding a new heat exchanger to create a 473 loop and resequencing when there are unconstrained upstream exchangers is the 
possibility of moving all the heat load of the selected upstream exchanger (exchanger with the highest $\Delta \mathrm{T}_{\mathrm{LM}}$ ) to a new exchanger further downstream without violating the network temperature constraint. If all the heat load of the upstream heat exchanger can be moved further downstream to a new exchanger, it will be a more economically 478 viable option to apply resequencing. For both resequencing and adding a new 479 exchanger to create a loop, the modifications are made relative to the upstream heat 480 exchanger with the highest $\Delta \mathrm{T}_{\mathrm{LM}}$. The heat exchanger with the highest $\Delta \mathrm{T}_{\mathrm{LM}}$ has the 481 greatest potential to relax the temperature constraint of the pinched exchanger. Figure 4828 shows an illustrative example. From Figure 8a, Exchangers 1 and 5 are upstream 483 from the pinched exchanger (Exchanger 2). Exchanger 1 should be selected for 484 analysis as it has the highest $\Delta \mathrm{T}_{\mathrm{LM}}$. Figure $8 \mathrm{~b}$ shows the appropriate placement for resequencing Exchanger 1. Moving Exchanger 1 downstream from the pinched exchanger relieves its temperature constraint as the inlet temperature of the pinched exchanger on the hot stream (1) increases. This allows for the pinched exchanger to 488 take up more heat load thereby, reducing the energy consumption of the utilities.

489 On the other hand, if there is a temperature constraint violation when resequencing is 490 performed, a new exchanger should be added to create a loop. Therefore, if it is 491 assumed that moving all the heat load of Exchanger 1 downstream violates the 492 temperature constraint of the network, a new exchanger $\mathrm{N}$ can be added to create a 493 loop with Exchanger 1. A certain amount of heat load $(\mathrm{H})$ can be transferred from 494 Exchanger 1 to the new exchanger N (see Figure 8c). By doing this, the temperature 495 constraint on the pinched exchanger is relaxed allowing for a reduction in energy 496 consumption.

497 In the second scenario, if there are no upstream heat exchangers from pinched 498 exchangers on either the hot or cold stream which the pinched exchangers are 
matched, adding a new exchanger to create a path or stream splitting will be the most

500 beneficial options. Adding a new exchanger to create a path is only possible if there

501 are viable utility exchangers not constrained by pinched exchanger(s) on the stream

502 with viable utility exchangers. To add a new exchanger to create a path, select the

503 utility exchangers with the highest duty or the utility exchanger that contributes to the

504 highest cross-pinch heat transfer. For stream splitting to be the most beneficial option,

505 there must be more than two pinched exchangers located adjacent to one another.

506 After identifying the first best option, the procedure is repeated sequentially until a

507 specified stopping criterion is met. Examples of stopping criteria that can be imposed 508 on the network are maximum energy recovery or a maximum number of 509 modifications.

\section{Combination of Structural Modifications with Enhancement}

511 This section presents a methodology for considering structural modifications based on 512 the pinch retrofit method alongside enhancement to achieve cost-effective energy 513 savings. By combining structural modifications with enhancement, the level of energy 514 savings obtained with structural modifications can be maintained but at a reduced 515 retrofit cost. Increasing the heat transfer area of existing exchangers is capital 516 intensive. However, a benefit of heat transfer enhancement is that an enhanced heat 517 exchanger has a higher heat transfer coefficient to exchange the same duty under 518 smaller heat transfer area requirements. In addition, implementation of enhancement 519 is less expensive as only minor modifications are required to the existing exchangers 520 making the process less expensive. Therefore, the retrofit cost can be reduced by 521 implementing heat transfer enhancement in place of increasing heat transfer area of 522 existing exchangers. The proposed retrofit methodology given in Figure 9 aims to 
provide maximum energy recovery, but at a reduced retrofit cost (increased retrofit profit).

525 Step 1: The pinch retrofit method is applied to the existing HEN to determine the best 526 structural modifications to meet the retrofit target. A consequence of performing 527 structural modifications is the additional heat transfer area requirement in existing 528 exchangers. Heat exchangers requiring additional area are identified in this step.

529 Step 2: The initial retrofit profit is represented by the difference between the profit 530 from energy savings and the total cost of retrofit as given in Equation 4. However, the 531 retrofit cost, in this case, is given by:
$\mathrm{RC}_{\mathrm{ex}}=\mathrm{SMC}_{\mathrm{ex}}+\mathrm{AC}_{\mathrm{ex}}+\mathrm{BC}_{\mathrm{ex}}$
$\forall_{\mathrm{ex}} \in \mathrm{EX}$
Equation 11

532 Where $\mathrm{SMC}_{\mathrm{ex}}$ is the cost of structural modifications, $\mathrm{AC}_{\mathrm{ex}}$ is the additional area cost, 533 and $\mathrm{BC}_{\mathrm{ex}}$ is the cost of bypass. The determination of utility cost is the same as that 534 given in Equations 6 and 7.

535 Step 3: Either sensitivity analysis or area ratio approach is used in identifying the best 536 heat exchanger among the heat exchangers requiring additional area to enhance. The 537 heat exchanger is enhanced by determining the maximum degree of enhancement 538 based on the exchanger geometry.

539 Step 4 and 4.1: The stream pressure drop of the enhanced exchanger is checked to 540 ensure that there are no violations. If the stream pressure drop after enhancement is 541 higher than the maximum of the stream, pressure drop mitigation techniques are used 542 to correct the violation. The best mitigation technique (for cases with more than one 543 option) is determined using the procedure outlined in Step 3 and 3.1 in Section 3. If 544 there is no stream pressure drop violation, continue to Step 5. 
545 Step 5: Calculate the new retrofit profit. Again, the retrofit profit is determined using

546 Equation 4, but the new retrofit cost is given by:

$\mathrm{RC}_{\mathrm{ex}}=\mathrm{SMC}_{\mathrm{ex}}+\mathrm{AC}_{\mathrm{ex}}+\mathrm{BC}_{\mathrm{ex}}+\mathrm{EC}_{\mathrm{ex}}+\mathrm{MC}_{\mathrm{ex}} \quad \forall_{\mathrm{ex}} \in \mathrm{EX} \quad$ Equation 12

547 Where $\mathrm{EC}_{\mathrm{ex}}$ is the cost of enhancement and $\mathrm{MC}_{\mathrm{ex}}$ is the cost of pressure drop

548 mitigation technique. The determination of utility cost is the same as that given in

549 Equations 6 and 7.

550 Step 6: If the new retrofit profit determined is Step 5 is less than initial retrofit profit

551 determined before applying heat transfer enhancement to a selected exchanger, the 552 retrofit procedure is stopped. This means that it is not economical to consider 553 enhancement alongside structural modifications. If the retrofit profit determined in 554 Step 5 is greater than the retrofit profit determined before applying heat transfer 555 enhancement to a selected exchanger, continue to Step 7.

556 Step 7: The network is analysed for other retrofit options by enhancing the next best 557 heat exchanger requiring additional area to eliminate or reduce its heat transfer area 558 requirements. The retrofit procedure is terminated when all exchangers requiring 559 additional area has been enhanced, i.e. no more opportunities to reduce the retrofit 560 cost.

\section{Case Study}

562 A simplified crude-oil preheat train is used to illustrate the application of the retrofit 563 methodologies in this work. Figure 10 shows the existing HEN structure. Tables 3, 4 564 and 5 shows the stream, exchanger and cost data respectively. 


\subsection{Heat Transfer Enhancement for a Fixed Network Structure}

566 Only tube-side enhancement techniques are considered in this case study, i.e. twisted 567 tape inserts. Therefore, the focus is placed on stream C1. The first step is to identify 568 the enhancement sequence. All process exchangers in the network are on a utility path 569 except Exchanger 7 that has been left out in the next immediate analysis. The two 570 methods (sensitivity analysis and area ratio approach) were used to identify the 571 enhancement sequence. Figure 11 shows the result of sensitivity analysis. Table 6 572 shows the results from the area ratio approach.

573 From analysing the results from sensitivity analysis and area ratio approach, both 574 methods identified the same enhancement sequence (see Figure 12). From Figure 12, 575 Exchanger 5 is identified as the best heat exchanger to enhance as it has the smallest 576 area ratio and brings about the greatest increase in the inlet temperature of the key 577 utility exchanger. The stream pressure drop is analysed after enhancing Exchanger 5. 578 The tube side pressure drop of Exchanger 5 has increased from $15.73 \mathrm{kPa}$ to $37.67 \mathrm{kPa}$. 579 This increase did not result in a stream pressure drop violation as the stream pressure 580 drop increased from $668.51 \mathrm{kPa}$ to $690.45 \mathrm{kPa}$, which is below the maximum allowable $581(700 \mathrm{kPa})$. Target temperature and heat transfer area violations are then corrected 582 using the non-linear optimisation model. The optimisation was carried out using the 583 LINDO system What's Best global solver [31]. Enhancing only Exchanger 5, resulted 584 in $\sim 3 \%$ decrease in energy consumption of the hot utility $\mathrm{H}$ with an initial utility 585 consumption of $14,455.41 \mathrm{~kW}$. The retrofit profit obtained was $\sim 3 \%$ of the initial 586 utility cost of \$5.8M.

587 Other opportunities for energy savings were explored by enhancing the next best heat 588 exchanger (Exchanger 1). By doing this, the maximum stream pressure drop was not 
589 violated as the pressure drop of Exchanger 1 only increased from an initial value of $590167.29 \mathrm{kPa}$ to $169.25 \mathrm{kPa}$. The energy savings after enhancing Exchanger 1 and 591 correcting the target temperature and heat transfer area violations amounted to $\sim 5.5 \%$ 592 of the initial utility consumption and a retrofit profit of $\sim 5.4 \%$ of the initial utility 593 cost. The retrofit profit is higher than that obtained after enhancing exchanger 5. 594 Therefore, the retrofit methodology is repeated. The next best exchanger for 595 enhancement is Exchanger 2. However, after enhancing Exchanger 2, the stream 596 pressure drop constraint was violated as the pressure drop of Exchanger 2 increased 597 from $131.40 \mathrm{kPa}$ to $163.31 \mathrm{kPa}$. The increase in the pressure drop of Exchanger 2 598 brought the total stream pressure drop to $724.32 \mathrm{kPa}$, which is above the maximum 599 allowable. The pressure drop violation is corrected using pressure drop mitigation 600 techniques. Exchanger 2 has two shells arranged in series and two tube passes. 601 Therefore, Equation 3 is used in determining the best mitigation technique by 602 evaluating the value of SF as the arrangement of the shells can be changed from series 603 to parallel and the number of tube passes can be reduced from two to one. A split 604 fraction of 0.5 is assumed for the case of changing shell arrangement. Table 7 shows 605 the results from applying both mitigation techniques. From Table 7, modifying the 606 shell arrangement from series to parallel is the best as it has the lowest value of SF, 607 which means that a higher degree of enhancement can still be obtained but at a lower 608 pressure drop penalty.

609 Apply enhancement based on the modified degree of enhancement and correcting 610 network violations, the retrofit profit is calculated. Figure 13 shows the retrofit result 611 after enhancing Exchanger 2 compared to that after enhancing Exchanger 5 and 612 Exchanger 5 and 1. From Figure 13, the retrofit profit after enhancing Exchanger 2 is 613 less than that after enhancing Exchanger 5 and 1. Therefore based on the stopping 
614 criterion (retrofit profit), the result obtained after enhancing Exchanger 2 is discarded,

615 and the retrofit methodology is stopped. Table 8 shows the final exchanger details

616 after enhancement.

617 Therefore, the final savings with only enhancement is $\sim 5.5 \%$ of the initial energy

618 consumption and $\sim 5.4 \%$ of the initial utility cost. The analysis shows that heat transfer

619 enhancement alone can bring about cost-effective energy saving. However, the energy

620 recovery by enhancement alone for a fixed network structure is limited.

\section{$621 \quad 5.2 \quad$ Structural Modifications (Pinch Retrofit Method)}

622 The objective with the application of the pinch retrofit method is to minimise the 623 energy consumption of the hot utility $\mathrm{H}$ subject to a $\Delta \mathrm{T}_{\min }$ of $10^{\circ} \mathrm{C}$. At this minimum 624 temperature approach, the expected decrease in energy consumption is $3,497 \mathrm{~kW}$. The 625 first step is to pinch the network by manipulating the existing degree of freedom. The 626 network has 6 process streams ( 5 hot streams and 1 cold stream) and 2 utility streams 627 (1 hot utility stream and 1 cold utility stream). The existing HEN shown in Figure 10 628 has 18 degrees of freedom (6 utility paths and 12 loops). Figure 14 shows the pinched 629 network structure. The pinch temperatures for this $\mathrm{HEN}$ are $40^{\circ} \mathrm{C}(\mathrm{Hot}) 30^{\circ} \mathrm{C}(\mathrm{Cold})$.

630 Pinched exchangers identified are 2, 4 and 6. Cross pinch heat exchangers are $\mathrm{C} 2$ and 631 C4 (cold utility exchangers used above the pinch). By pinching the network, a 632 decrease in energy consumption of $13.9 \%$ is obtained, but this comes at additional 633 heat transfer area penalty. The degrees of freedom decrease after pinching the network 634 from 18 to 5 as the duties of the utility exchangers C1and C3 goes to zero thereby 635 eliminating 4 utility paths and 9 loops. Note that all analysis has been carried out 636 using the SPRINT software [29]. 
637 The best modification is either the application of resequencing or adding a new 638 exchanger to create a loop. This is because there is at least one upstream process heat 639 exchanger upstream from all pinched exchangers on either the hot or cold stream on 640 which the pinched exchangers are matched, i.e. Exchangers 1, 3 and 7.

641 The next step is to check the feasibility of moving the upstream exchanger with the 642 highest $\Delta \mathrm{T}_{\mathrm{LM}}$ to the exit of the pinched exchanger most downstream and on a utility 643 path. The $\Delta \mathrm{T}_{\mathrm{LM}}$ of the upstream exchangers 1,3 and 7 are $20.47^{\circ} \mathrm{C}, 56.9^{\circ} \mathrm{C}$ and $64482.1^{\circ} \mathrm{C}$. Therefore; the analysis is carried out relative to Exchanger 7. To check the 645 feasibility of moving all the heat load of Exchanger 7, a new heat exchanger is placed 646 at the exit of Exchanger 4 (represents the pinched exchanger most downstream and on 647 a utility path) to create a loop with Exchanger 7. The analysis found that all the heat 648 load of exchanger 7 could be moved without violating the network feasibility. 649 Therefore, resequencing was identified as the best option. Figure 15 shows the result 650 after the application of resequencing. Figures $16-18$ shows the retrofit result for the 651 other modification options. It can be noted that adding a new exchanger to create a 652 loop provided the same decrease in energy consumption of the hot utility. However, 653 the duty of the existing exchanger, 7 , goes to zero as all the heat load is transferred to 654 the new exchanger. Compared to resequencing, adding a new exchanger will not be 655 the best option as the best retrofit option seeks to maximise the use of existing 656 equipment as opposed to investing in new equipment to meet the same objective.

657 The decrease in energy consumption after resequencing is less than the targeted 658 savings. The network data is updated and the retrofit procedure repeated. The second 659 modification identified based on the retrofit algorithm was to add a new exchanger to 660 create a loop. This is because there are still two upstream exchangers from all pinched 661 exchangers, Exchangers 1 and 3. The new exchanger is added to create a loop as 
662 shown in Figure 19 as Exchanger 3 has the higher $\Delta \mathrm{T}_{\mathrm{LM}}\left(59.01^{\circ} \mathrm{C}\right)$ compared to

663 Exchanger $1\left(18.72^{\circ} \mathrm{C}\right)$. After the second modification, the retrofit target is achieved.

664 Therefore, the retrofit process is stopped.

665 Table 9 shows the final heat exchanger data after performing structural modifications.

666 The total additional area required in existing exchangers after performing structural

667 modifications is $\sim 1,760 \mathrm{~m}^{2}$. The calculated retrofit profit after structural modifications

668 is $\sim 3 \%$ of the initial utility cost. However, this does not consider the cost associated

669 with production losses due to the time required to carry out the modifications and civil

670 engineering and piping work required to make the modifications. Also, these

671 modifications might be difficult to implement due to topology, safety and downtime

672 constraints imposed by the existing network.

\section{$673 \quad 5.3$ Combination of Structural Modifications and Enhancement}

674 The objective is to maximise energy recovery subject to a $\Delta \mathrm{T}_{\min }$ of $10^{\circ} \mathrm{C}$ while

675 maximising retrofit profit. The final network structure for maximum energy recovery

676 is given in Figure 19. From Table 9, all existing process heat exchangers require 677 additional area except Exchanger 3. Therefore, Exchanger 3 has been left out from

678 this analysis. Figure 20 shows the sequence for obtaining the retrofit target.

679 Enhancement is applied based on the enhancement sequence shown. Note that 680 pressure drop mitigation techniques were only required when two exchangers 681 (Exchangers 2 and 7) were enhanced. Also, there was no stopping criterion violation.

682 Therefore, all candidate heat exchangers were enhanced to meet the retrofit objective.

683 Table 10 shows the final exchanger data after the application of the combination of 684 structural modifications with enhancement. Figure 21 shows a comparative analysis of 685 the different retrofit options presented in this work. The result shows that by 
686

combining structural modifications with enhancement, high energy recovery can be obtained with high retrofit profit unlike the use of only structural modifications or enhancement.

\section{Conclusions}

New retrofit methodologies for HENs based on the application of heat transfer enhancement considering pressure drop constraints, structural modifications and a combination of both methods have been presented in this work. The benefits of these methodologies have been demonstrated with a case study. The results show that the application of enhancement alone can bring about cost-effective energy savings, but the degree of energy savings is limited, i.e. achieving only $5.5 \%$ of the HEN initial utility consumption. This is because the energy savings by enhancement for a fixed network structure is constrained by the geometry of existing exchangers, which governs the maximum degree of enhancement that can be obtained. The potential for more energy recovery was exploited by considering the application of structural modifications based on the new pinch retrofit method. The new pinch retrofit method can identify the best location to apply a series of modifications and the best structural modifications for maximum energy recovery with the least number of modifications. Higher energy savings (24.2\% of initial utility consumption) was obtained but at a higher capital investment penalty. Heat transfer enhancement is used to curb the high investment required for performing structural modifications while maintaining the energy savings at a reduced retrofit cost. As such, the energy savings of $24.2 \%$ is maintained with approximately $65 \%$ increase in retrofit profit compared to the retrofit profit after performing structural modifications. The new insights provided by the combination of the pinch retrofit method and the use of heat transfer enhancement is 
710 believed to be a considerable contribution owing to its robustness, which lends itself 711 to be applied to different HENs.

712

\section{Nomenclature}

\section{Symbols}

A

$\mathrm{A}_{\mathrm{E}}$

$A_{R}$

$\mathrm{AC}$

$\mathrm{BC}$

$\mathrm{CCU}$

CHU

$\mathrm{CP}$

EC

$\mathrm{F}_{\mathrm{T}}$

$\mathrm{h}_{\mathrm{S}}$

$\mathrm{h}_{\mathrm{T}}$

MC

OT

Q

$\mathrm{RC}$

RP

SF

SF

SMC

\section{Definitions}

Heat transfer area

Area after enhancement

Area ratio

Additional area cost

By-pass cost

Cost parameter for cold utility

Cost parameter for hot utility

Heat capacity flowrate

Enhancement cost

Correction factor

Shell-side heat transfer coefficient

Tube-side heat transfer coefficient

Mitigation cost

Operating time

Duty

Retrofit cost

Retrofit profit

Selection factor

Selection factor

Structural modification cost

\section{Units}

$\mathrm{m}^{2}$

$\mathrm{m}^{2}$

$\$$

$\$$

$\$ / y$

$\$ / y$

$\mathrm{kW} /{ }^{\circ} \mathrm{C}$

$\$$

$\mathrm{kW} \mathrm{m}{ }^{-2} \mathrm{C}^{-1}$

$\mathrm{kW} \mathrm{m}{ }^{-2} \mathrm{C}^{-1}$

$\$$

$\mathrm{y}$

$\mathrm{kW}$

$\$$

$\$$

$\$$ 
TCOS

THOS

TS

TT

$\mathrm{U}$

$\mathrm{U}_{\mathrm{E}}$

$\Delta \mathrm{A}$

$\Delta \mathrm{P}$

$\Delta \mathrm{P}_{\mathrm{B}}$

$\Delta \mathrm{P}_{\mathrm{S}}$

$\Delta \mathrm{P}_{\mathrm{T}}$

$\Delta \mathrm{T}_{\mathrm{LM}}$

$\Delta \mathrm{T}_{\min }$
Target temperature of cold streams

Target temperature of hot streams

Supply temperature

Target temperature

Overall heat transfer coefficient

Enhanced overall heat transfer coefficient

Additional area

Pressure drop

Stream total pressure drop

Total shell-side pressure drop

Total tube-side pressure drop

Log mean temperature difference

Minimum temperature approach
${ }^{\circ} \mathrm{C}$

${ }^{\circ} \mathrm{C}$

${ }^{\circ} \mathrm{C}$

${ }^{\circ} \mathrm{C}$

$\mathrm{kW} \mathrm{m}{ }^{-2} \mathrm{C}^{-1}$

$\mathrm{kW} \mathrm{m}{ }^{-2}{ }^{\circ} \mathrm{C}^{-1}$

$\mathrm{m}^{2}$

$\mathrm{kPa}$

$\mathrm{kPa}$

$\mathrm{kPa}$

$\mathrm{kPa}$

${ }^{\circ} \mathrm{C}$

${ }^{\circ} \mathrm{C}$

\section{Subscripts:}

B

$\mathrm{B}, \mathrm{E}$

CS

CU

E

ex, EX

f

HS

HU
Base

Base and enhanced

Cold stream

Cold utility

Enhanced

Exchanger

Final

Hot stream

Hot utility 
i

$\mathrm{N}$

$\mathrm{N}, \mathrm{E}$

S

SM

$\mathrm{T}$
Initial

New

New and enhanced

Shell

Structural modification

Tube

\section{References}

716 [1] Liu ZY, Jobson M. Retrofit design for increasing the processing capacity of distil-

717 lation columns: 1. A hydraulic performance indicator. Chemical Engineering Re718 search and Design. 2004;82(1):3-9.

719 [2] Sreepathi BK, Rangaiah GP. Review of heat exchanger network retrofitting meth720 odologies and their applications. Industrial and Engineering Chemistry Research. $721 \quad 2014 ; 53(28): 11205-20$.

722 [3] Smith R. Chemical Process Design and Integration. John Wiley \& Sons; 2016.

723 [4] Tjoe TN, Linnhoff B. Using pinch technology for process retrofit. Chemical Engi724 neering. 1986;93(8):47-60.

725 [5] Carlsson A, Franck PA, Berntsson T. Design better heat exchanger network retro726 fits. Chemical Engineering Progress;(United States). 1993;89(3).

727 [6] Gadalla MA. A new graphical method for Pinch Analysis applications: Heat ex728 changer network retrofit and energy integration. Energy. 2015; 81:159-74.

729 [7] Grossmann IE. Mixed-integer nonlinear programming techniques for the synthesis 730 of engineering systems. Research in Engineering Design. 1990;1(3):205-28.

731 [8] Ciric AR, Floudas CA. A comprehensive optimization model of the heat 732 exchanger network retrofit problem. Heat Recovery Systems and CHP. 
734 [9] Ma KL, Hui CW, Yee TF. Constant approach temperature model for HEN retrofit. 735 Applied thermal engineering. 2000;20(15):1505-33.

736 [10] Yee TF, Grossmann IE. A screening and optimization approach for the retrofit 737 of heat-exchanger networks. Industrial and engineering chemistry research. $738 \quad$ 1991;30(1):146.

739 [11] Dolan WB, Cummings PT, Le Van MD. Algorithmic efficiency of simulated 740 annealing for heat exchanger network design. Computers and chemical engineer$741 \quad$ ing. 1990;14(10):1039-50.

742 [12] López-Maldonado LA, Ponce-Ortega JM, Segovia-Hernández JG. Multiobjec743 tive synthesis of heat exchanger networks minimizing the total annual cost and the 744 environmental impact. Applied Thermal Engineering. 2011;31(6):1099-113.

745 [13] Asante ND, Zhu XX. An automated approach for heat exchanger network ret746 rofit featuring minimal topology modifications. Computers and chemical engi747 neering. 1996;20: S7-12.

748 [14] Smith R, Jobson M, Chen L. Recent development in the retrofit of heat ex749 changer networks. Applied Thermal Engineering. 2010;30(16):2281-9.

750 [15] Bakhtiari B, Bedard S. Retrofitting heat exchanger networks using a modified 751 Network Pinch approach. Applied Thermal Engineering. 2013;51(1):973-9.

752 [16] Pan M, Jamaliniya S, Smith R, Bulatov I, Gough M, Higley T, Droegemueller 753 P. New insights to implement heat transfer intensification for shell and tube heat $754 \quad$ exchangers. Energy. 2013; 57:208-21.

755 [17] Pan M, Bulatov I, Smith R. Efficient retrofitting approach for improving heat 756 recovery in heat exchanger networks with heat transfer intensification. Industrial 757 and Engineering Chemistry Research. 2014;53(27):11107-20. 
758 [18] Wang Y, Pan M, Bulatov I, Smith R, Kim JK. Application of intensified heat 759 transfer for the retrofit of heat exchanger network. Applied Energy. 2012 Jan $760 \quad 31 ; 89(1): 45-59$.

761 [19] Jiang N, Shelley JD, Doyle S, Smith R. Heat exchanger network retrofit with a 762 fixed network structure. Applied Energy. 2014; 127:25-33.

763 [20] Akpomiemie MO, Smith R. Retrofit of heat exchanger networks without to764 pology modifications and additional heat transfer area. Applied Energy. 2015; $765 \quad 159: 381-90$.

766 [21] Akpomiemie MO, Smith R. Retrofit of heat exchanger networks with heat 767 transfer enhancement based on an area ratio approach. Applied Energy. 2016; $768 \quad 165: 22-35$.

769 [22] Polley GT, Panjeh Shahi MH, Jegede FO. Pressure drop considerations in the 770 retrofit of heat exchanger networks. Transactions of the Institute of Chemical En$771 \quad$ gineers. 1990;68.

772 [23] Nie XR, Zhu XX. Heat exchanger network retrofit considering pressure drop 773 and heat-transfer enhancement. AIChE Journal. 1999;45(6):1239-54.

774 [24] Pan M, Bulatov I, Smith R. Improving heat recovery in retrofitting heat ex775 changer networks with heat transfer intensification, pressure drop constraint and 776 fouling mitigation. Applied Energy. 2016; 161:611-26.

777 [25] Akpomiemie MO, Smith R. Pressure drop considerations with heat transfer 778 enhancement in heat exchanger network retrofit. Applied Thermal Engineering. $779 \quad 2017 ; 116: 695-708$.

780 [26] Shenoy UV. Heat exchanger network synthesis: process optimization by ener$781 \quad$ gy and resource analysis. Gulf Professional Publishing; 1995.

782 [27] Rajeswaran A, Narasimhan S. Network topology identification using PCA and 
its graph theoretic interpretations. arXiv preprint arXiv:1506.00438. 2015.

784 [28] Sprint. v.2.9. Centre for Process Integration: University of Manchester.2016.

785 [29] Jiang N, Shelley JD, Smith R. New models for conventional and heat ex786 changers enhanced with tube inserts for heat exchanger network retrofit. Applied 787 Thermal Engineering. 2014;70(1):944-56.

788 [30] Akpomiemie MO. Cost effective retrofit methods for heat exchanger networks 789 (Doctoral dissertation, University of Manchester). 2016.

790 [31] LINDO A. 12.0 User Manual; LINDO System. Inc.: Chicago, IL, USA. 2013. 791 792 793 794 795 796 797 798 799 800 801 802 803 804 805 806 
Table 1: Initial Incidence Matrix

\begin{tabular}{|c|cccccccc|}
\hline $\mathrm{S} / \mathrm{E}$ & 1 & 2 & 3 & 4 & $\mathrm{C} 1$ & $\mathrm{C} 2$ & $\mathrm{H}$ & $\mathrm{P}$ \\
\hline 1 & 0 & 0 & +1 & 0 & +1 & 0 & 0 & 0 \\
2 & 0 & 0 & 0 & +1 & 0 & +1 & 0 & 0 \\
3 & +1 & +1 & 0 & 0 & 0 & 0 & 0 & 0 \\
4 & 0 & -1 & -1 & 0 & 0 & 0 & 0 & 0 \\
5 & -1 & 0 & 0 & -1 & 0 & 0 & -1 & 0 \\
$\mathrm{HU}$ & 0 & 0 & 0 & 0 & 0 & 0 & +1 & +1 \\
$\mathrm{CU}$ & 0 & 0 & 0 & 0 & -1 & -1 & 0 & -1 \\
\hline
\end{tabular}

809

810

Table 2: Reduced Incidence Matrix

\begin{tabular}{|c|cccccccc|}
\hline $\mathrm{S} / \mathrm{E}$ & 1 & 2 & 3 & 4 & $\mathrm{C} 1$ & $\mathrm{C} 2$ & $\mathrm{H}$ & $\mathrm{P}$ \\
\hline 1 & 0 & 0 & +1 & 0 & +1 & 0 & 0 & 0 \\
2 & 0 & 0 & 0 & +1 & 0 & +1 & 0 & 0 \\
3 & +1 & +1 & 0 & 0 & 0 & 0 & 0 & 0 \\
4 & 0 & -1 & 0 & 0 & +1 & 0 & 0 & 0 \\
5 & 0 & 0 & 0 & 0 & +1 & +1 & -1 & 0 \\
$\mathrm{HU}$ & 0 & 0 & 0 & 0 & 0 & 0 & +1 & +1 \\
$\mathrm{CU}$ & 0 & 0 & 0 & 0 & 0 & 0 & 0 & 0 \\
\hline
\end{tabular}

811

812 Table 3: Stream Data

\begin{tabular}{|c|c|c|c|c|c|}
\hline Stream & $\mathrm{CP}\left[\mathrm{kW} /{ }^{\circ} \mathrm{C}\right]$ & $\mathrm{TS}\left[{ }^{\circ} \mathrm{C}\right]$ & $\mathrm{TT}\left[{ }^{\circ} \mathrm{C}\right]$ & $\mathrm{Q}[\mathrm{kW}]$ & Maximum $\Delta \mathrm{P}(\mathrm{kPa})$ \\
\hline $\mathrm{H} 1$ & 86 & 310 & 95 & $18,490.0$ & 400 \\
\hline $\mathrm{H} 2$ & 21.4 & 299 & 120 & $3,830.6$ & 200 \\
\hline
\end{tabular}




\begin{tabular}{|c|c|c|c|c|c|} 
H3 & 184.7 & 273 & 250 & $4,248.1$ & 200 \\
\hline H4 & 23.5 & 230 & 95 & $3,172.5$ & 200 \\
\hline H5 & 129.4 & 206 & 178 & $3,623.2$ & 100 \\
\hline C1 & 143.91 & 52 & 360 & $44,323.2$ & 700 \\
\hline HU & 72.3 & 500 & 300 & 14455.4 & - \\
\hline CU & 349.7 & 20 & 30 & 3496.6 & - \\
\hline
\end{tabular}

\section{Table 4: Exchanger Data}

\begin{tabular}{|c|c|c|c|c|c|c|c|}
\hline Ex. & $\mathrm{A}\left(\mathrm{m}^{2}\right)$ & $\begin{array}{c}\mathrm{h}_{\mathrm{s}} \\
\left(\mathrm{kW} / \mathrm{m}^{2 \circ} \mathrm{C}\right)\end{array}$ & $\begin{array}{c}\Delta \mathrm{P}_{\mathrm{S}} \\
(\mathrm{kPa})\end{array}$ & $\begin{array}{c}\mathrm{h}_{\mathrm{T}} \\
\left(\mathrm{kW} / \mathrm{m}^{2 \circ} \mathrm{C}\right)\end{array}$ & $\begin{array}{c}\Delta \mathrm{P}_{\mathrm{T}} \\
(\mathrm{kPa})\end{array}$ & $\begin{array}{c}\mathrm{U} \\
\left(\mathrm{kW} / \mathrm{m}^{2 \circ} \mathrm{C}\right)\end{array}$ & $\mathrm{Q}(\mathrm{kW})$ \\
\hline 1 & 396.72 & 2.07 & 78.49 & 1.33 & 167.29 & 0.52 & 6141.33 \\
\hline 2 & 545.45 & 2.31 & 100.80 & 1.40 & 131.40 & 0.48 & 6134.83 \\
\hline 3 & 633.85 & 4.54 & 75.76 & 0.78 & 73.43 & 0.16 & 5556.61 \\
\hline 4 & 354.64 & 1.27 & 4.27 & 0.62 & 45.38 & 0.10 & 2688.79 \\
\hline 5 & 183.85 & 2.56 & 98.38 & 0.78 & 15.73 & 0.32 & 3431.16 \\
\hline 6 & 843.73 & 0.96 & 14.66 & 0.49 & 146.74 & 0.06 & 2291.88 \\
\hline 7 & 114.28 & 3.38 & 91.09 & 0.98 & 88.54 & 0.36 & 3623.20 \\
\hline $\mathrm{C} 1$ & - & - & & - & & - & 657.23 \\
\hline $\mathrm{C} 2$ & - & - & & - & & - & 1141.81 \\
\hline C3 & - & - & & - & & - & 816.94 \\
\hline $\mathrm{C} 4$ & - & - & & - & & - & 880.62 \\
\hline $\mathrm{H}$ & - & - & & - & & - & 14455.41 \\
\hline
\end{tabular}

\section{Table 5: Cost Data}




\begin{tabular}{|c|c|}
\hline CHU: $400(\$ / \mathrm{kW} y)$ & EC: $500+10^{*} \mathrm{~A}(\$)$ \\
\hline CCU: $5.5(\$ / \mathrm{kW} y)$ & BC: $500(\$)$ \\
\hline Payback operating time: $1 \mathrm{y}$ & Cost of increasing heat exchanger area: $4,000+200^{*} \mathrm{~A}(\$)$ \\
\cline { 2 - 2 } & Cost of resequencing: $10,000(\$)$ \\
\cline { 2 - 2 } & Cost of new heat exchanger: $4,000+300^{*} \mathrm{~A}(\$)$ \\
\cline { 2 - 2 } & Cost of modifying shell arrangement: $10,000(\$)$ \\
\cline { 2 - 2 } & Cost of modifying tube passes: $5,000(\$)$ \\
\cline { 2 - 2 } & \\
\cline { 2 - 2 } &
\end{tabular}

815

816 Table 6: Results from the Area Ratio Approach

\begin{tabular}{|c|c|c|c|}
\hline Exchangers & $\mathrm{U}\left(\mathrm{kW} / \mathrm{m}^{2 \circ} \mathrm{C}\right)$ & $\mathrm{U}_{\mathrm{E}}\left(\mathrm{kW} / \mathrm{m}^{2 \circ} \mathrm{C}\right)$ & $\mathrm{A}_{\mathrm{R}}$ \\
\hline 1 & 0.517 & 0.669 & 0.773 \\
\hline 2 & 0.475 & 0.597 & 0.795 \\
\hline 3 & 0.158 & 0.198 & 0.798 \\
\hline 4 & 0.0963 & 0.108 & 0.891 \\
\hline 5 & 0.325 & 0.448 & 0.725 \\
\hline 6 & 0.610 & 0.674 & 0.905 \\
\hline
\end{tabular}

817

818

Table 7: Application of pressure drop mitigation techniques for Exchanger 2

\begin{tabular}{|c|c|c|c|}
\cline { 2 - 3 } \multicolumn{1}{c|}{} & $\begin{array}{r}\text { Tube pass reduction } \\
\text { (two to one) }\end{array}$ & $\begin{array}{c}\text { Shell arrangement } \\
\text { modification } \\
\text { (series to parallel) }\end{array}$ \\
\hline \multirow{3}{*}{ Base Case } & $\mathrm{U}_{\mathrm{B}}\left(\mathrm{kW} / \mathrm{m}^{2 \circ} \mathrm{C}\right)$ & \multicolumn{2}{|c|}{0.475} \\
\cline { 2 - 4 } & $\mathrm{U}_{\mathrm{B}, \mathrm{E}}\left(\mathrm{kW} / \mathrm{m}^{2 \circ} \mathrm{C}\right)$ & \multicolumn{2}{|c|}{0.597} \\
\cline { 2 - 4 } & $\Delta \mathrm{P}_{\mathrm{B}}(\mathrm{kPa})$ & \multicolumn{2}{|c|}{131.40} \\
\hline
\end{tabular}




\begin{tabular}{|c|c|c|c|}
\hline & $\Delta \mathrm{P}_{\mathrm{B}, \mathrm{E}}(\mathrm{kPa})$ & \multicolumn{2}{|c|}{163.31} \\
\hline \multirow{4}{*}{$\begin{array}{c}\text { After } \\
\text { Modifications }\end{array}$} & $\mathrm{U}_{\mathrm{N}}\left(\mathrm{kW} / \mathrm{m}^{2 \circ} \mathrm{C}\right)$ & 0.356 & 0.361 \\
\hline & $\mathrm{U}_{\mathrm{N}, \mathrm{E}}\left(\mathrm{kW} / \mathrm{m}^{2 \circ} \mathrm{C}\right)$ & 0.490 & 0.494 \\
\hline & $\Delta \mathrm{P}_{\mathrm{N}}(\mathrm{kPa})$ & 113.80 & 33.77 \\
\hline & $\Delta \mathrm{P}_{\mathrm{N}, \mathrm{E}}(\mathrm{kPa})$ & 125.48 & 43.22 \\
\hline \multicolumn{2}{|c|}{$\mathbf{S F}$} & 0.33 & 0.27 \\
\hline
\end{tabular}

Table 8: Final Heat Exchanger Data after Enhancement

\begin{tabular}{|c|c|c|c|c|c|c|c|}
\hline Ex & $\mathrm{A}\left(\mathrm{m}^{2}\right)$ & $\begin{array}{c}\mathrm{U} \\
\left(\mathrm{kW} / \mathrm{m}^{2 \circ} \mathrm{C}\right)\end{array}$ & $\begin{array}{r}\Delta \mathrm{T}_{\mathrm{LM}} \\
\left({ }^{\circ} \mathrm{C}\right)\end{array}$ & $\mathrm{F}_{\mathrm{T}}$ & $\mathrm{Q}(\mathrm{kW})$ & $\begin{array}{l}\Delta \mathrm{P}_{\mathrm{T}} \\
(\mathrm{kPa})\end{array}$ & $\begin{array}{l}\Delta \mathrm{P}_{\mathrm{S}} \\
(\mathrm{kPa})\end{array}$ \\
\hline 1 & 396.72 & 0.67 & 28.29 & 0.88 & 6104.73 & 169.25 & 78.49 \\
\hline 2 & 545.45 & 0.48 & 29.00 & 0.82 & 6162.68 & 131.40 & 100.80 \\
\hline 3 & 633.85 & 0.16 & 62.80 & 0.88 & 5561.54 & 73.43 & 75.76 \\
\hline 4 & 354.64 & 0.10 & 84.06 & 0.94 & 2688.32 & 45.38 & 4.27 \\
\hline 5 & 183.85 & 0.45 & 53.53 & 0.96 & 4230.13 & 37.67 & 98.38 \\
\hline 6 & 843.73 & 0.06 & 46.00 & 0.97 & 2291.21 & 146.74 & 14.66 \\
\hline 7 & 114.28 & 0.36 & 88.76 & 0.97 & 3623.20 & 88.54 & 91.09 \\
\hline $\mathrm{C} 1$ & - & - & - & - & 661.04 & - & - \\
\hline $\mathrm{C} 2$ & - & - & - & - & 1142.28 & - & - \\
\hline $\mathrm{C} 3$ & - & - & - & - & 17.97 & - & - \\
\hline C4 & - & - & - & - & 881.29 & - & - \\
\hline $\mathrm{H}$ & - & - & - & - & 13661.52 & - & - \\
\hline
\end{tabular}


825 Table 9: Heat Exchanger Data after Structural Modifications

\begin{tabular}{|c|c|c|c|c|c|}
\hline Ex. & $\mathrm{A}\left(\mathrm{m}^{2}\right)$ & $\mathrm{A}_{\mathrm{SM}}\left(\mathrm{m}^{2}\right)$ & $\mathrm{U}\left(\mathrm{kW} / \mathrm{m}^{2 \circ} \mathrm{C}\right)$ & $\mathrm{Q}(\mathrm{kW})$ & $\mathrm{Q}_{\mathrm{SM}}(\mathrm{kW})$ \\
\hline 1 & 396.72 & 451.96 & 0.52 & 6141.33 & 3449.98 \\
\hline 2 & 545.45 & 550.45 & 0.48 & 6134.83 & 5351.40 \\
\hline 3 & 633.85 & 475.44 & 0.16 & 5556.61 & 3449.94 \\
\hline 4 & 354.64 & 569.73 & 0.10 & 2688.79 & 3830.60 \\
\hline 5 & 183.85 & 826.71 & 0.32 & 3431.16 & 4248.10 \\
\hline 6 & 843.73 & 906.89 & 0.06 & 2291.88 & 3172.50 \\
\hline 7 & 114.28 & 892.97 & 0.36 & 3623.20 & 3623.20 \\
\hline $\mathrm{N}$ & - & 1177.16 & 0.25 & - & 6338.68 \\
\hline $\mathrm{C} 1$ & - & - & - & 657.23 & 0 \\
\hline $\mathrm{C} 2$ & - & - & - & 114.81 & 0 \\
\hline $\mathrm{C} 3$ & - & - & - & 816.94 & 0 \\
\hline $\mathrm{C} 4$ & - & - & - & 880.62 & 0 \\
\hline $\mathrm{H}$ & - & - & - & 14455.41 & 10958.81 \\
\hline
\end{tabular}

826

827 Table 10: Final Exchanger Details

\begin{tabular}{|c|c|c|c|c|c|c|c|}
\hline Ex. & $\mathrm{A}\left(\mathrm{m}^{2}\right)$ & $\mathrm{A}_{\mathrm{SM}}\left(\mathrm{m}^{2}\right)$ & $\mathrm{A}_{\mathrm{E}}\left(\mathrm{m}^{2}\right)$ & $\begin{array}{c}\mathrm{U}_{\mathrm{B}} \\
\left(\mathrm{kW} / \mathrm{m}^{2}{ }^{\circ} \mathrm{C}\right)\end{array}$ & $\begin{array}{c}\mathrm{U}_{\mathrm{E}} \\
\left(\mathrm{kW} / \mathrm{m}^{2}{ }^{\circ} \mathrm{C}\right)\end{array}$ & $\mathrm{Q}_{\text {в }}(\mathrm{kW})$ & $\mathrm{Q}_{\mathrm{SM}}(\mathrm{kW})$ \\
\hline 1 & 396.72 & 451.96 & 349.53 & 0.52 & 0.67 & 6141.33 & 3449.98 \\
\hline 2 & 545.45 & 550.45 & 529.27 & 0.48 & 0.49 & 6134.83 & 5351.40 \\
\hline 3 & 633.85 & 475.44 & 475.44 & 0.16 & 0.16 & 5556.61 & 3449.94 \\
\hline 4 & 354.64 & 569.73 & 507.47 & 0.10 & 0.11 & 2688.79 & 3830.60 \\
\hline 5 & 183.85 & 826.71 & 599.67 & 0.32 & 0.45 & 3431.16 & 4248.10 \\
\hline
\end{tabular}




\begin{tabular}{|c|c|c|c|c|c|c|c|}
\hline 6 & 843.73 & 906.89 & 820.84 & 0.06 & 0.07 & 2291.88 & 3172.50 \\
\hline 7 & 114.28 & 892.97 & 808.60 & 0.36 & 0.40 & 3623.20 & 3623.20 \\
\hline $\mathrm{N}$ & - & 1177.16 & - & 0.25 & - & - & 6338.68 \\
\hline $\mathrm{C} 1$ & - & - & - & - & - & 657.23 & 0 \\
\hline $\mathrm{C} 2$ & - & - & - & - & - & 114.81 & 0 \\
\hline $\mathrm{C} 3$ & - & - & - & - & - & 816.94 & 0 \\
\hline $\mathrm{C} 4$ & - & - & - & - & - & 880.62 & 0 \\
\hline $\mathrm{H}$ & - & - & - & - & - & 14455.41 & 10958.81 \\
\hline
\end{tabular}

828

829

830

831

832

833

834

835

836

837

838

839

840

841

842

843

844

845 


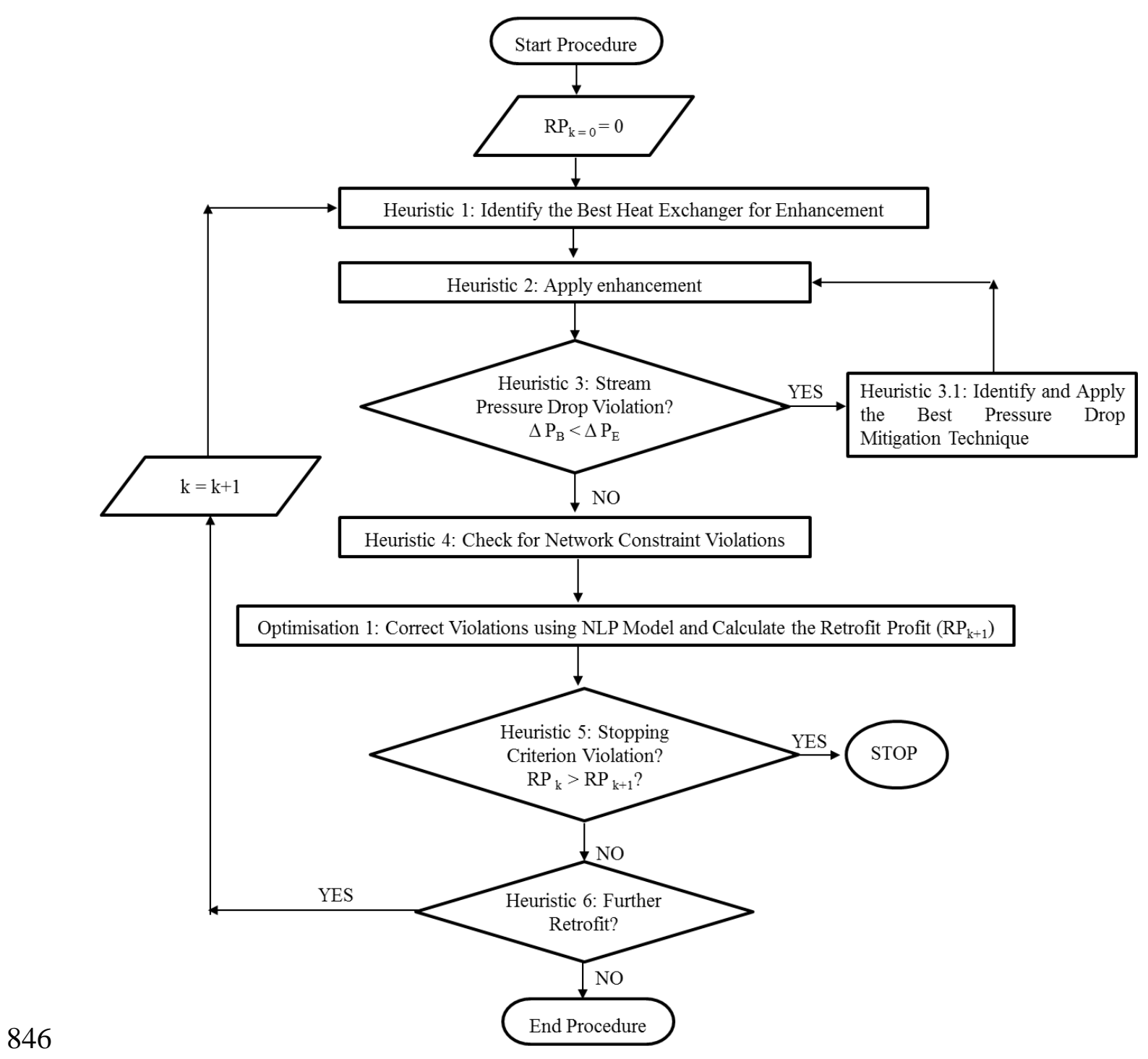

847 Figure 1: Retrofit methodology with pressure drop and heat transfer enhancement

848

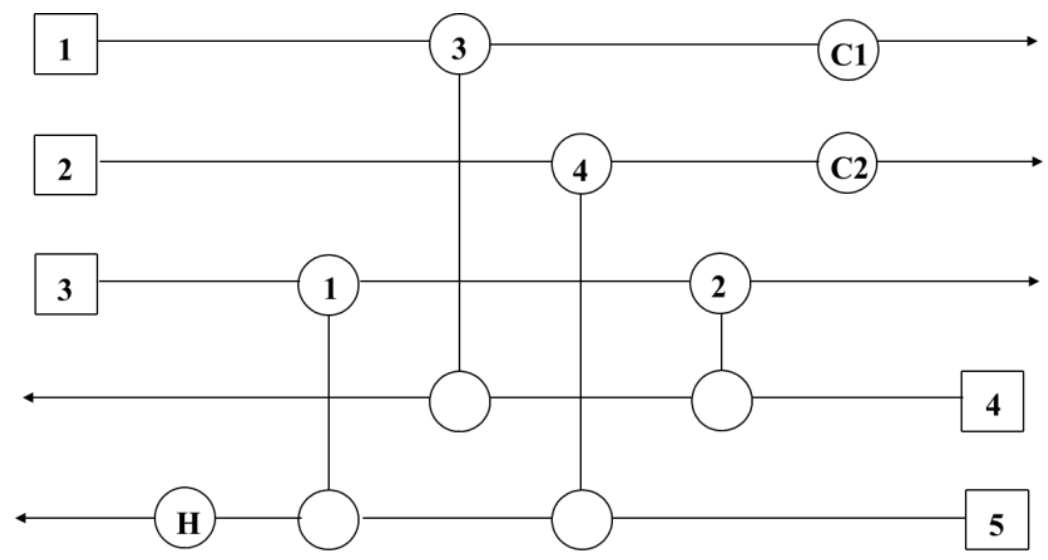




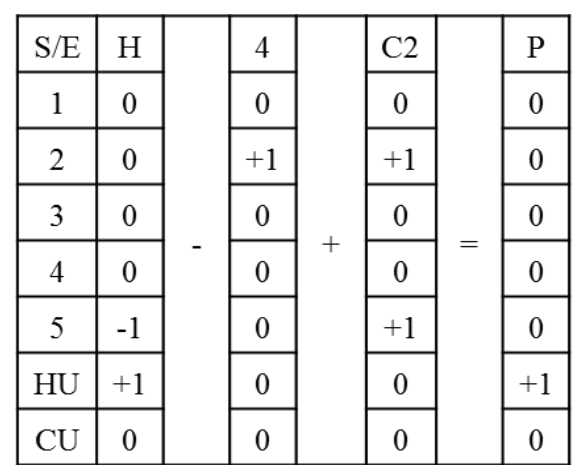

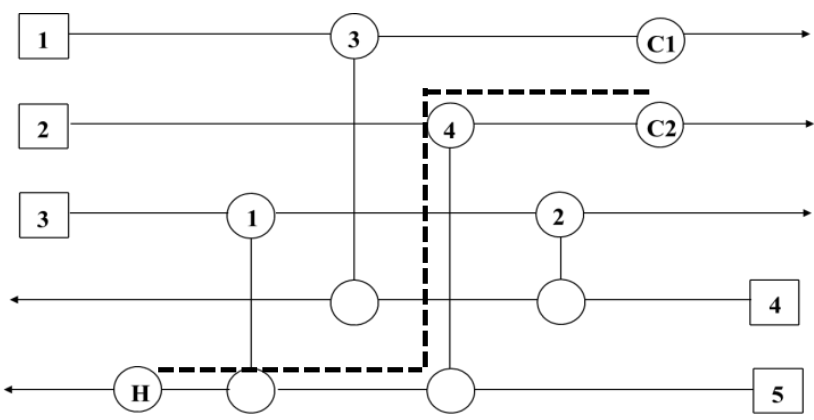

Figure 3: First Utility Path

853

854

\begin{tabular}{|c|c|c|c|c|c|c|c|}
\hline S/E & $\mathrm{H}$ & 1 & 2 & 3 & C & & 1 \\
\hline 1 & 0 & 0 & 0 & +1 & + & & 0 \\
\hline 2 & 0 & 0 & 0 & 0 & 0 & & 0 \\
\hline 3 & 0 & +1 & +1 & 0 & 0 & & 0 \\
\hline 4 & 0 & 0 & -1 & 0 & + & & 0 \\
\hline 5 & -1 & 0 & 0 & 0 & + & & 0 \\
\hline $\mathrm{HU}$ & +1 & 0 & 0 & 0 & 0 & & +1 \\
\hline $\mathrm{CU}$ & 0 & 0 & 0 & 0 & 0 & & 0 \\
\hline
\end{tabular}

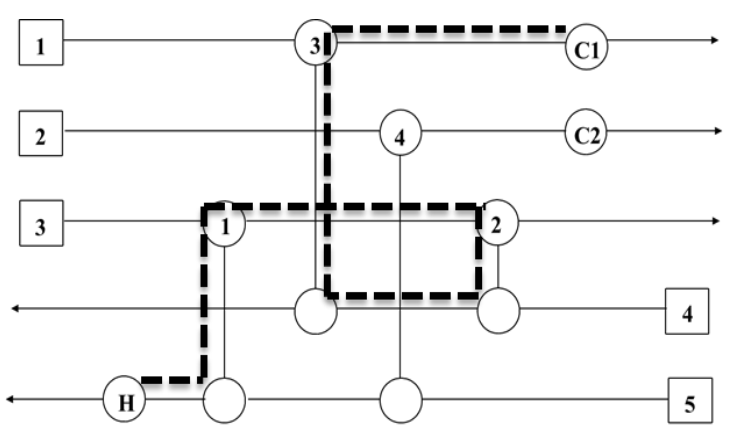

855

856

Figure 4: Second Utility Path

857

858

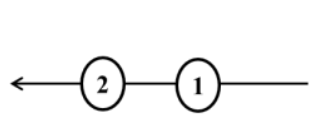

Series arrangement $\Delta \mathbf{P}_{\text {series }}=\Delta \mathbf{P}_{1}+\Delta \mathbf{P}_{\mathbf{2}}$

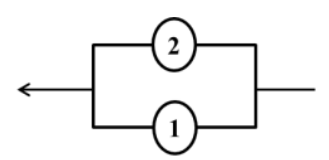

Parallel arrangement

$\Delta \mathbf{P}_{\text {parallel }}=\mathbf{M a x}\left(\Delta \mathbf{P}_{1}, \Delta \mathbf{P}_{2}\right)$

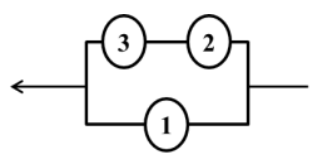

Mixed arrangement

$\Delta \mathbf{P}_{\text {mixed1 }}=\operatorname{Max}\left(\Delta \mathrm{P}_{2}+\Delta \mathrm{P}_{3}, \Delta \mathrm{P}_{1}\right)$

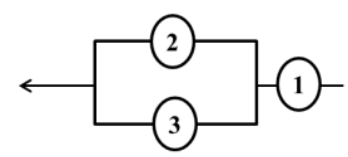

Mixed arrangement

$\Delta \mathbf{P}_{\text {mixed2 }}=\Delta \mathbf{P}_{1}+\operatorname{Max}\left(\Delta \mathbf{P}_{2}, \Delta \mathbf{P}_{3}\right)$

Figure 5: Different shell arrangements and pressure drop calculation 


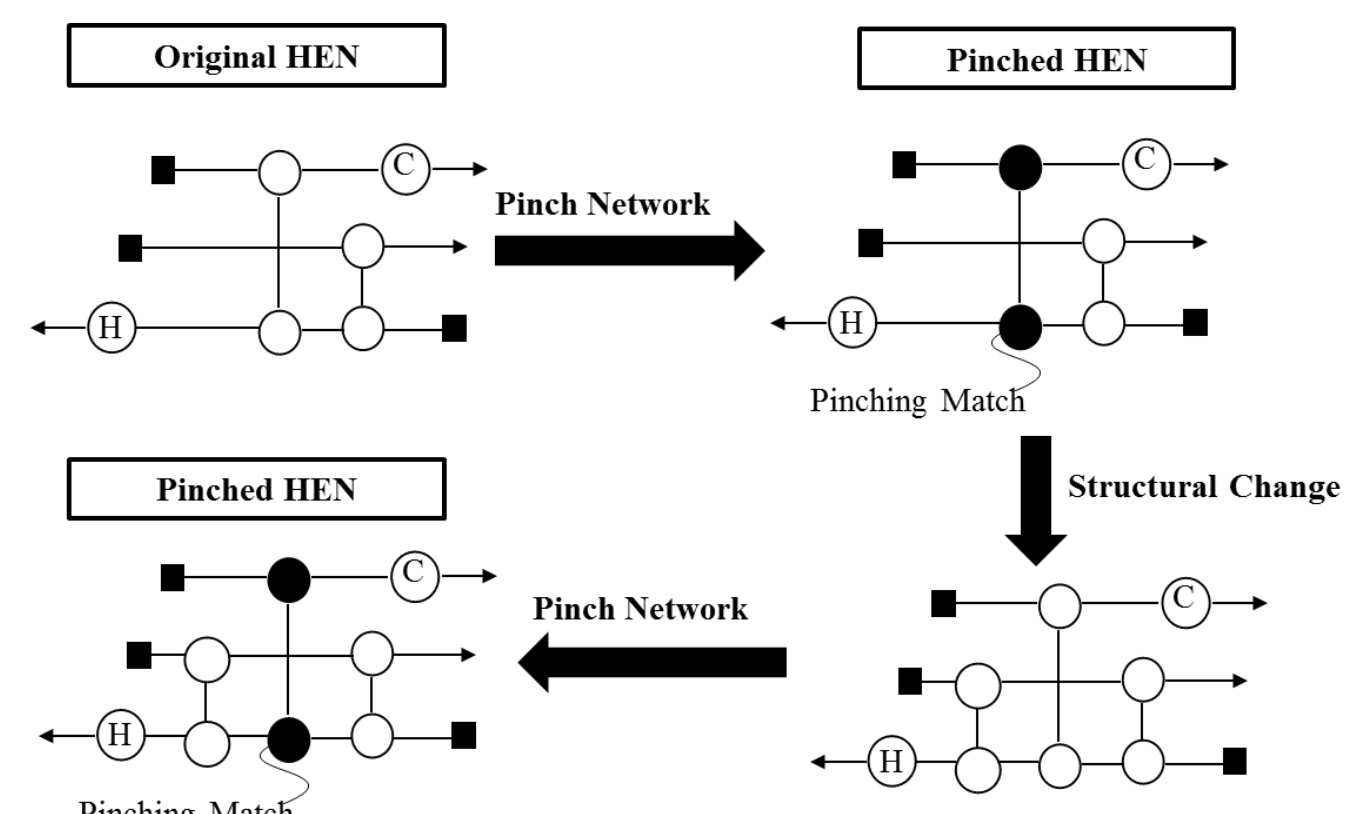

Pinching Match

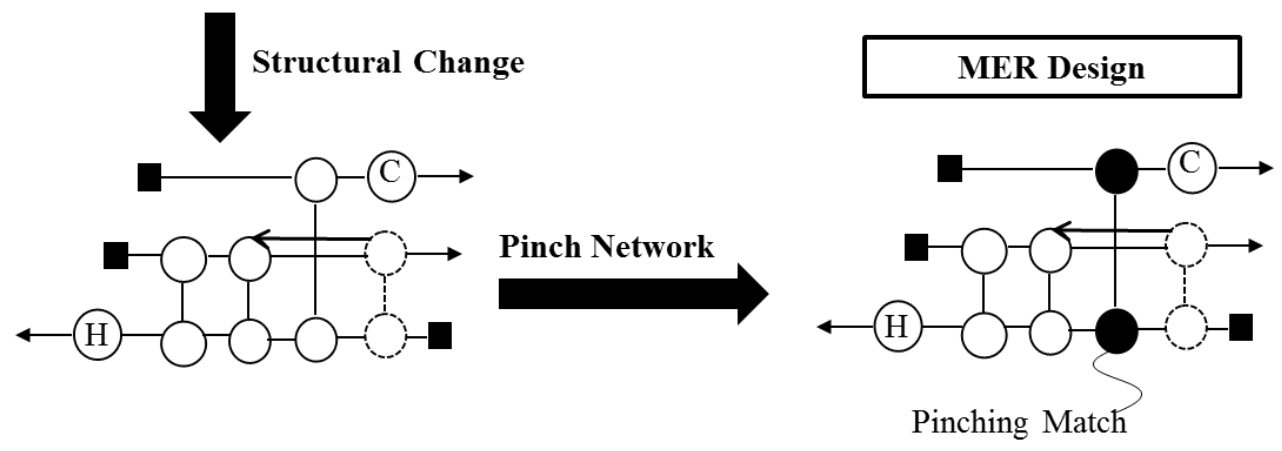

Figure 6: Background of pinch retrofit method

863

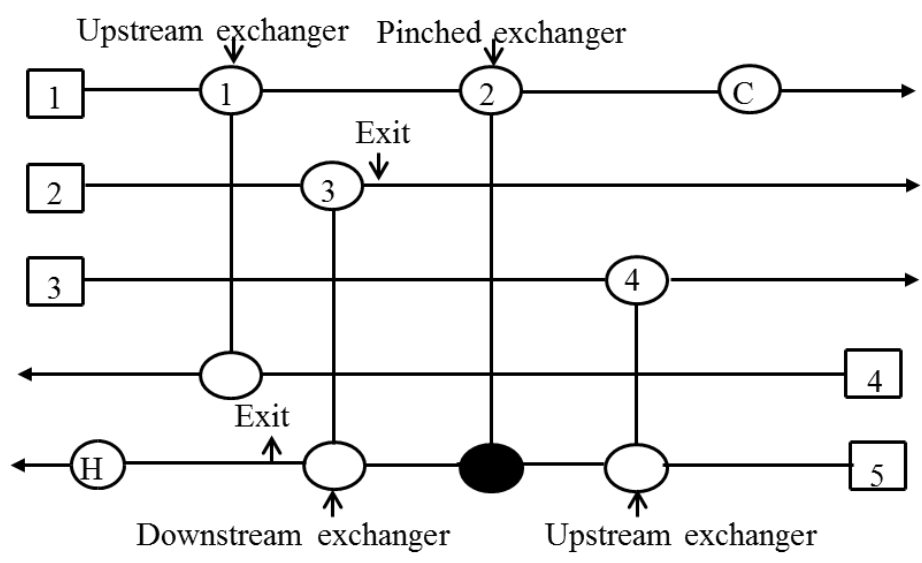

Figure 7: Simple illustration for key terms 
(a)

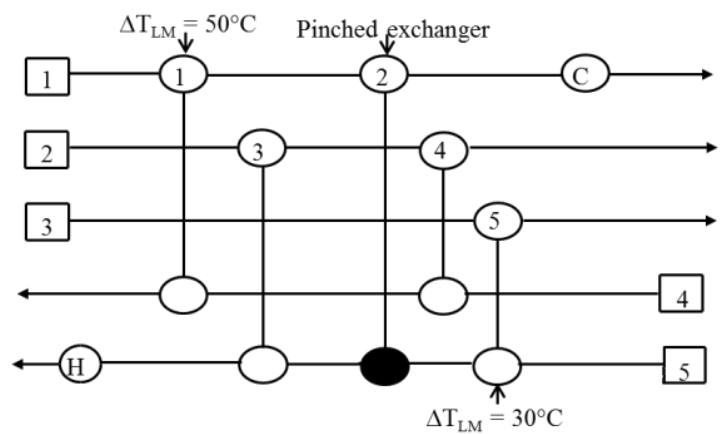

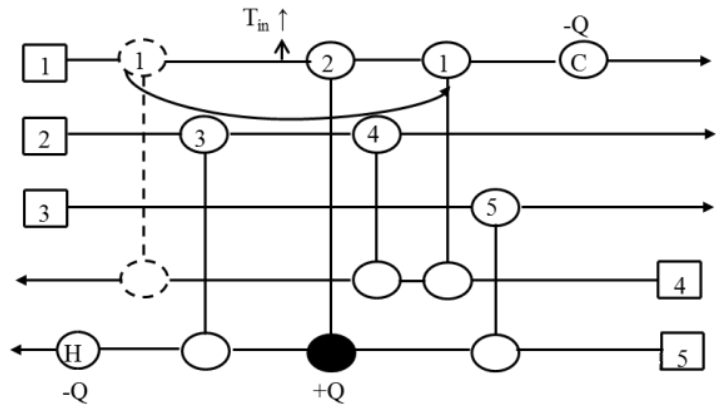

(b)

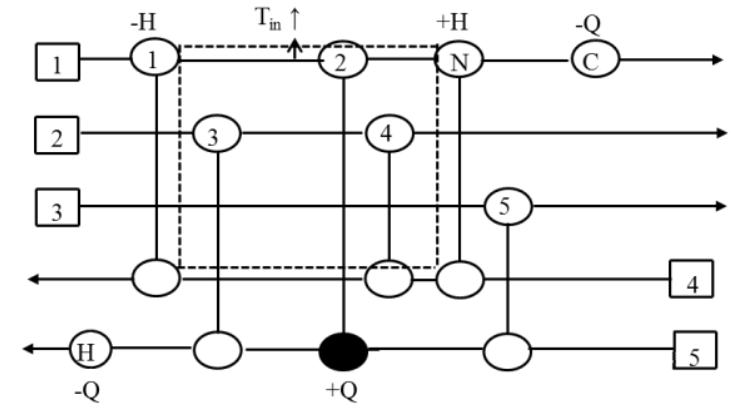

(c)
867

868

869

870

871

872

Figure 8: Illustrative example for upstream exchangers 

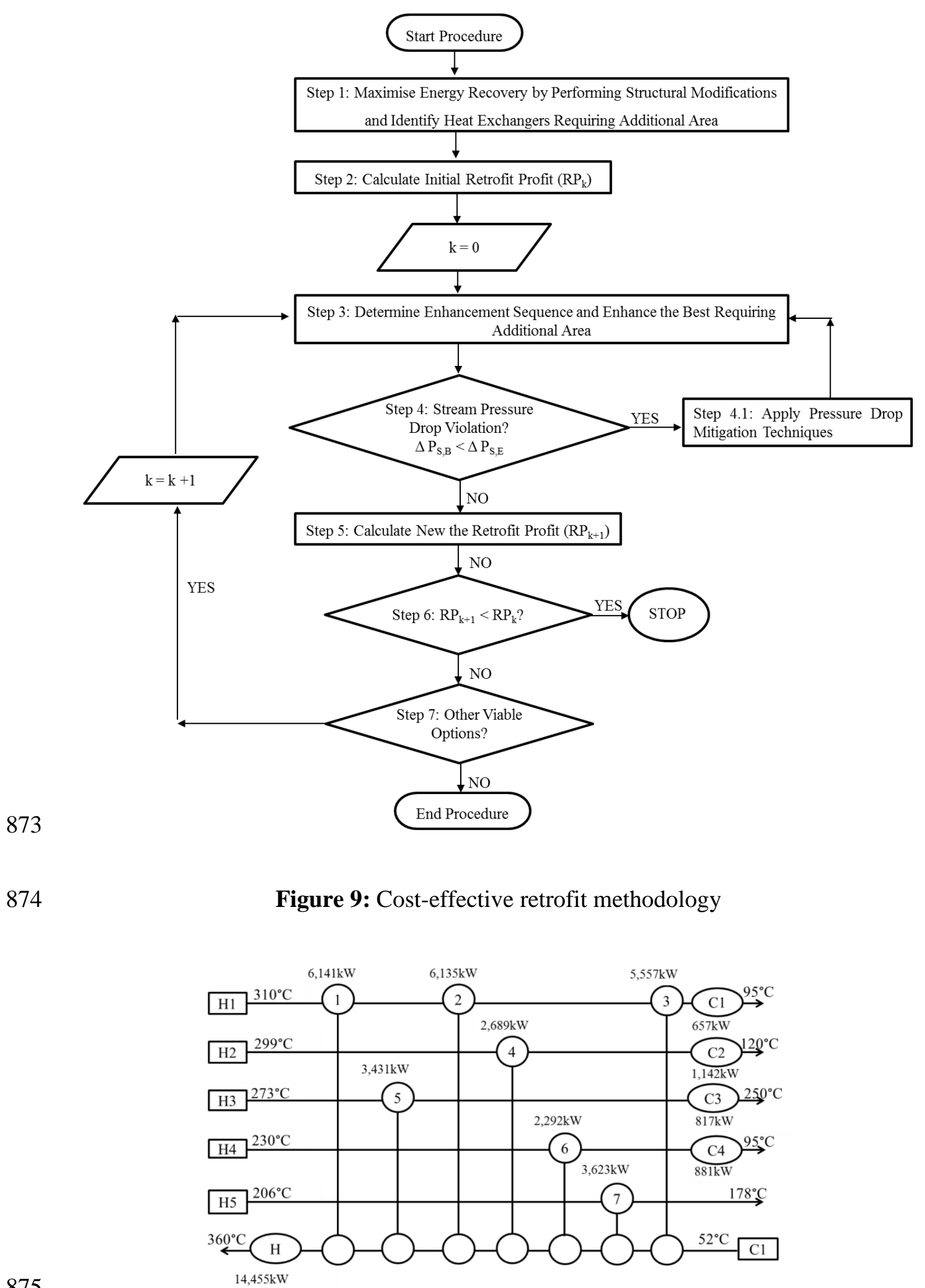


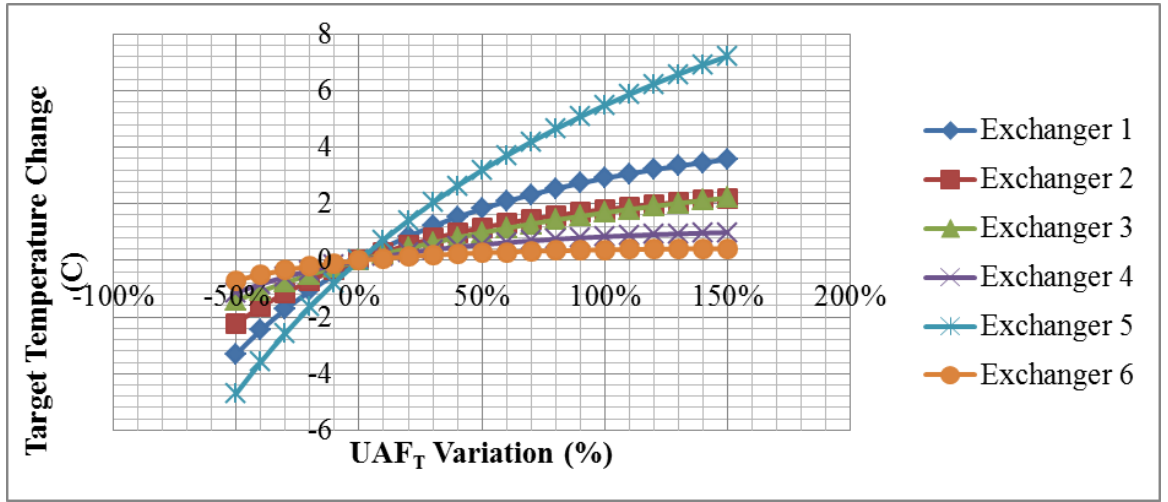

Figure 11: Sensitivity Analysis Result

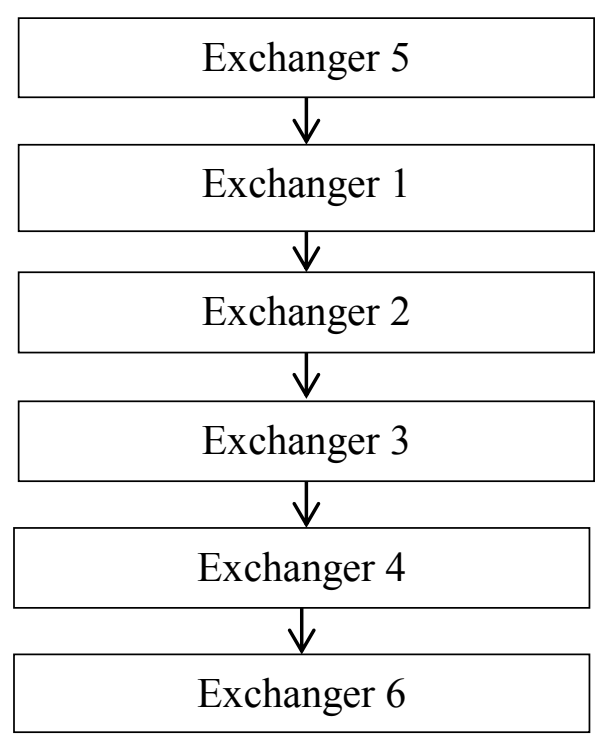

Figure 12: Enhancement Sequence

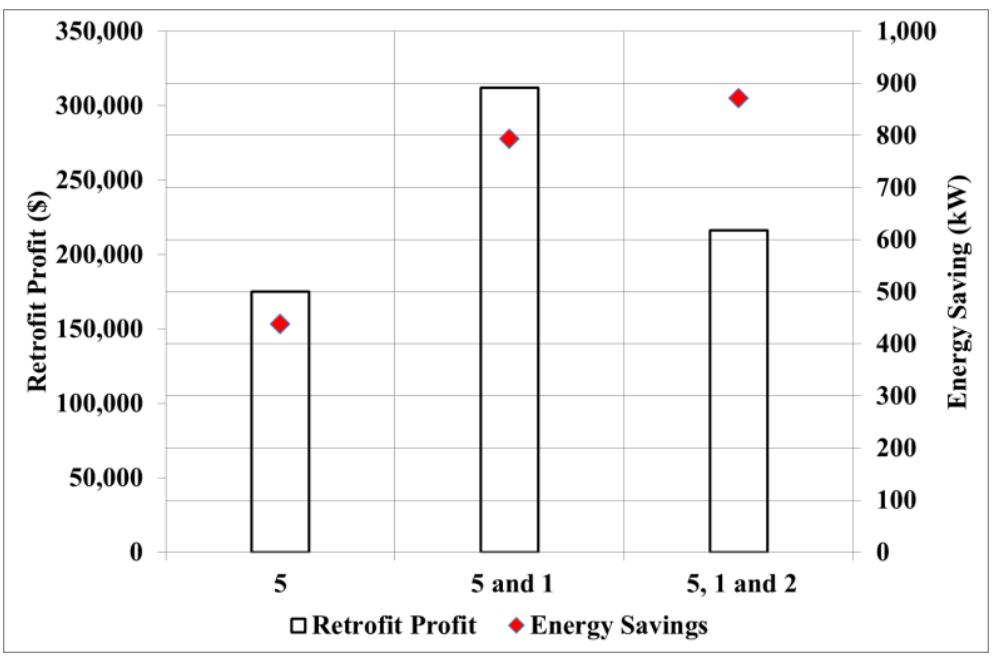

Figure 13: Comparison of enhancement results 
883

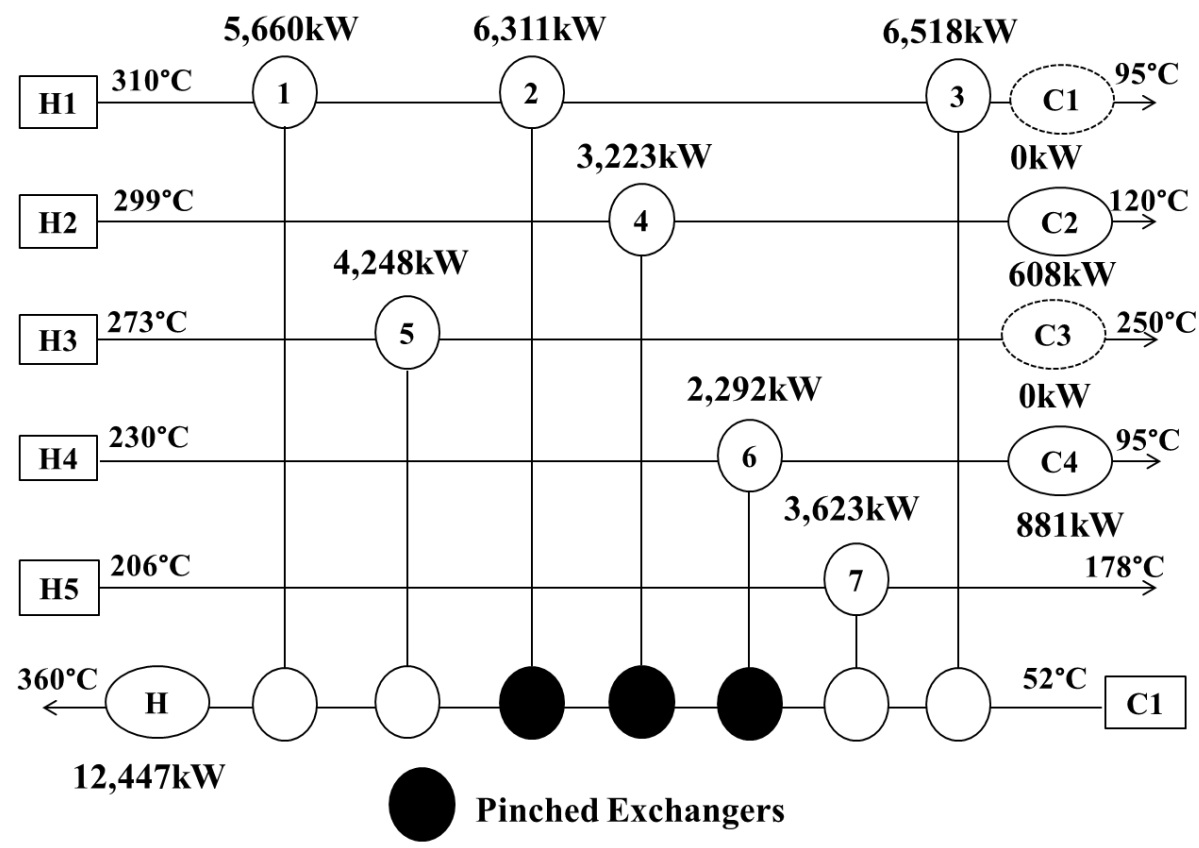

884

Figure 14: Pinched HEN

885

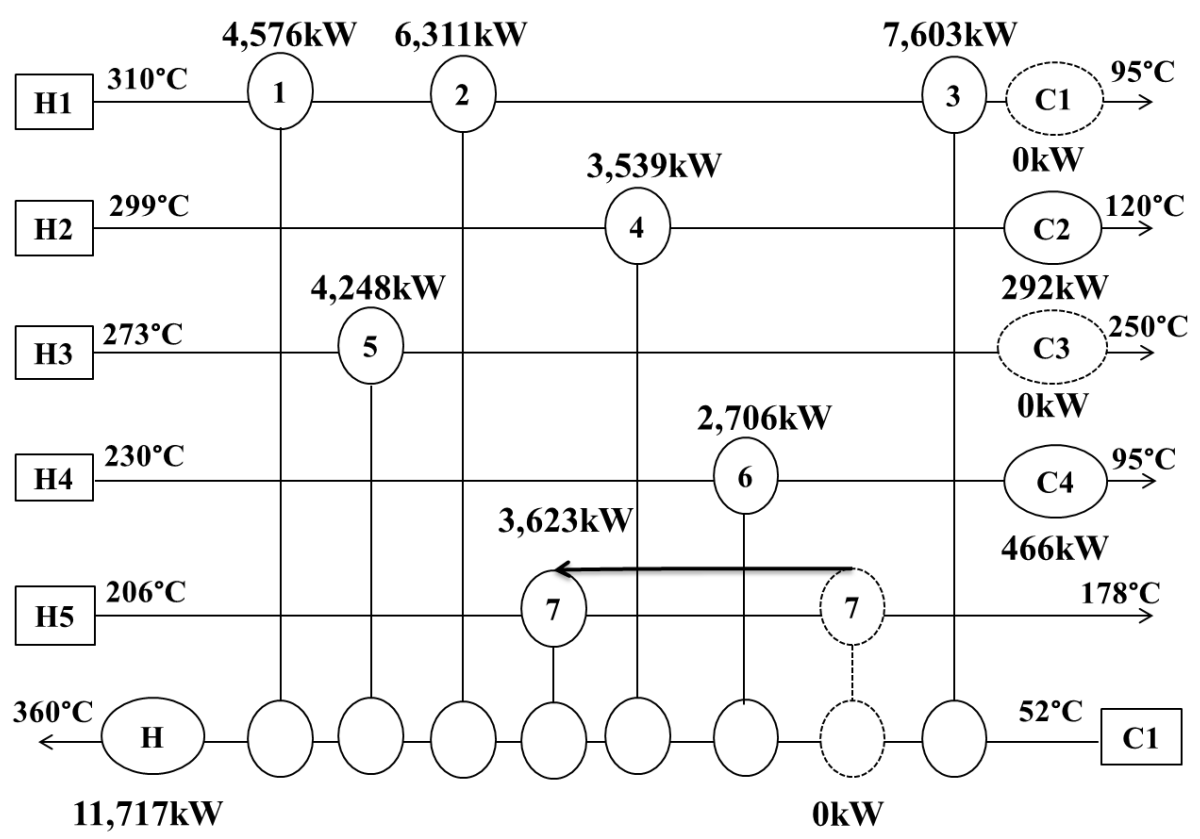

886

Figure 15: HEN after resequencing 


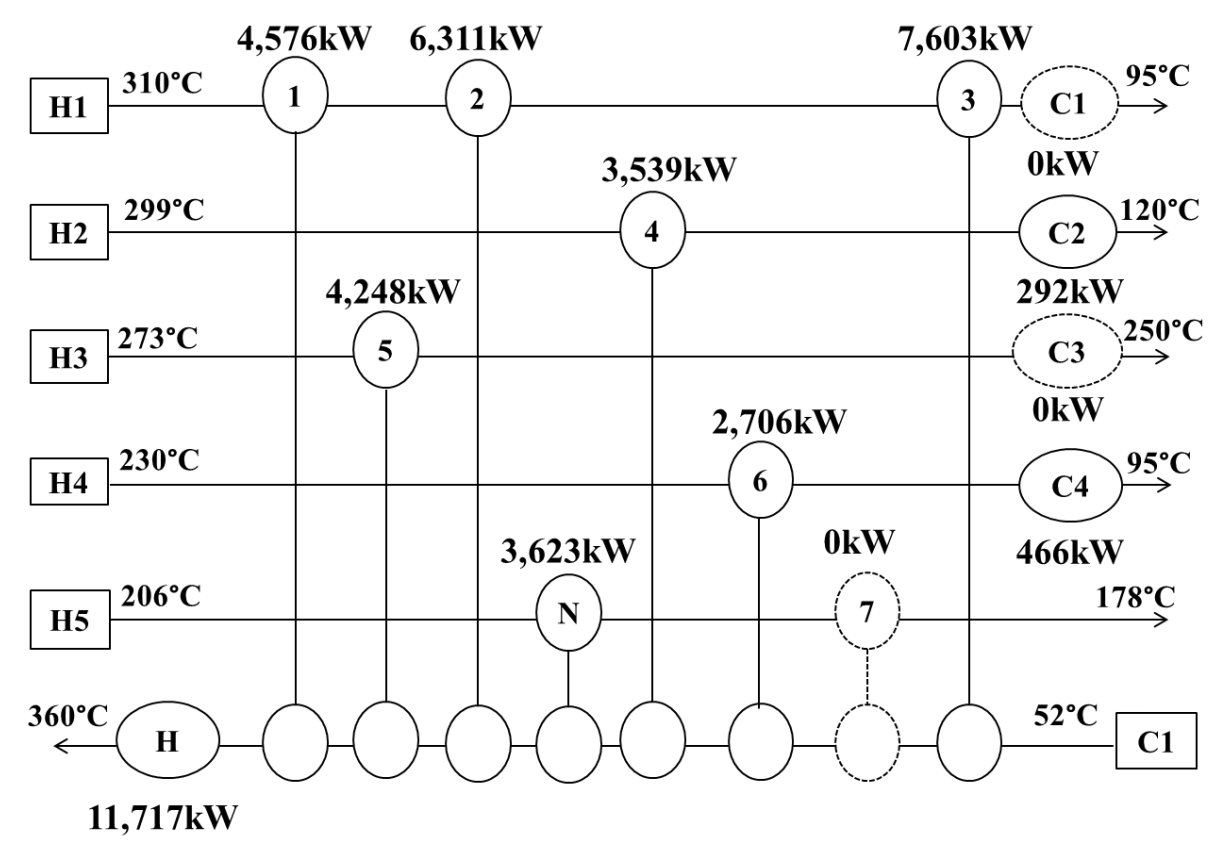

889

890

Figure 16: HEN after adding a new exchanger to create a loop

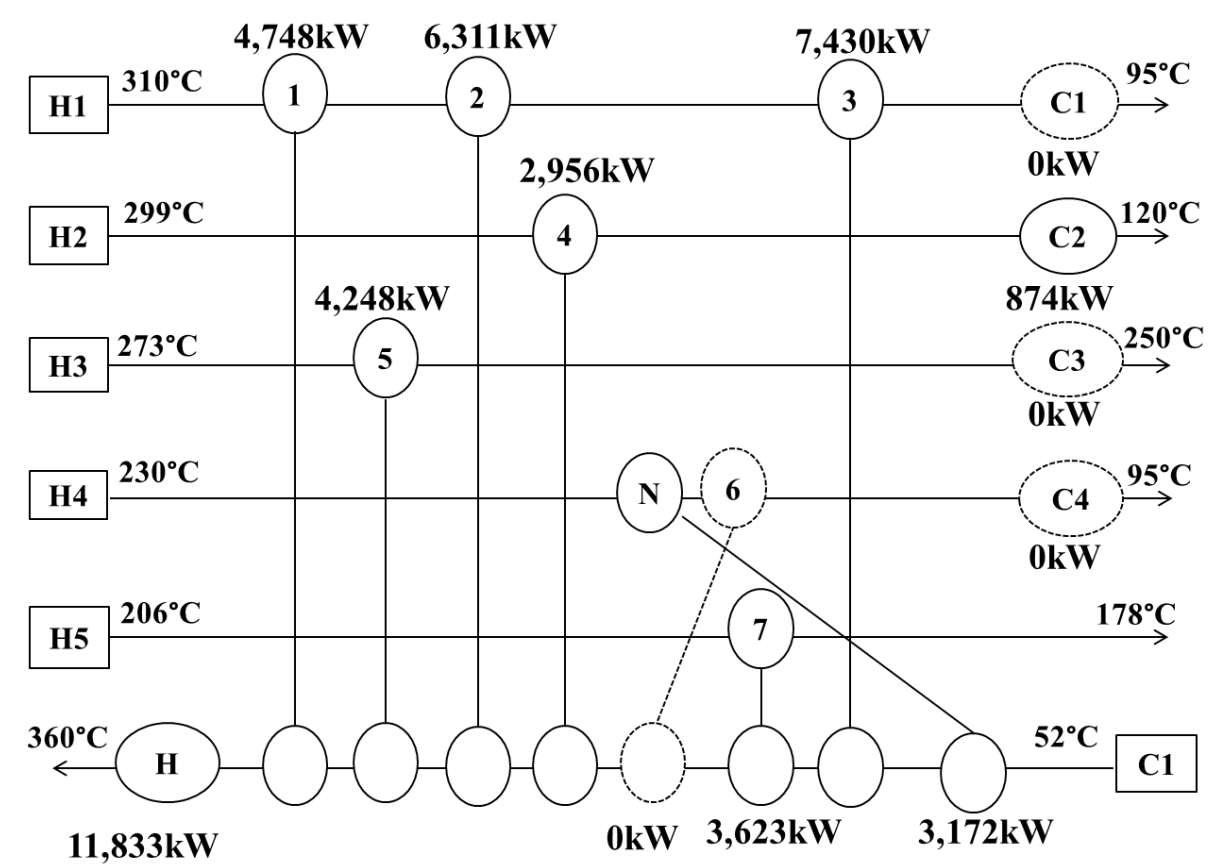

891

892

893

Figure 17: HEN after adding a new exchanger to create a utility path

894 
895

896

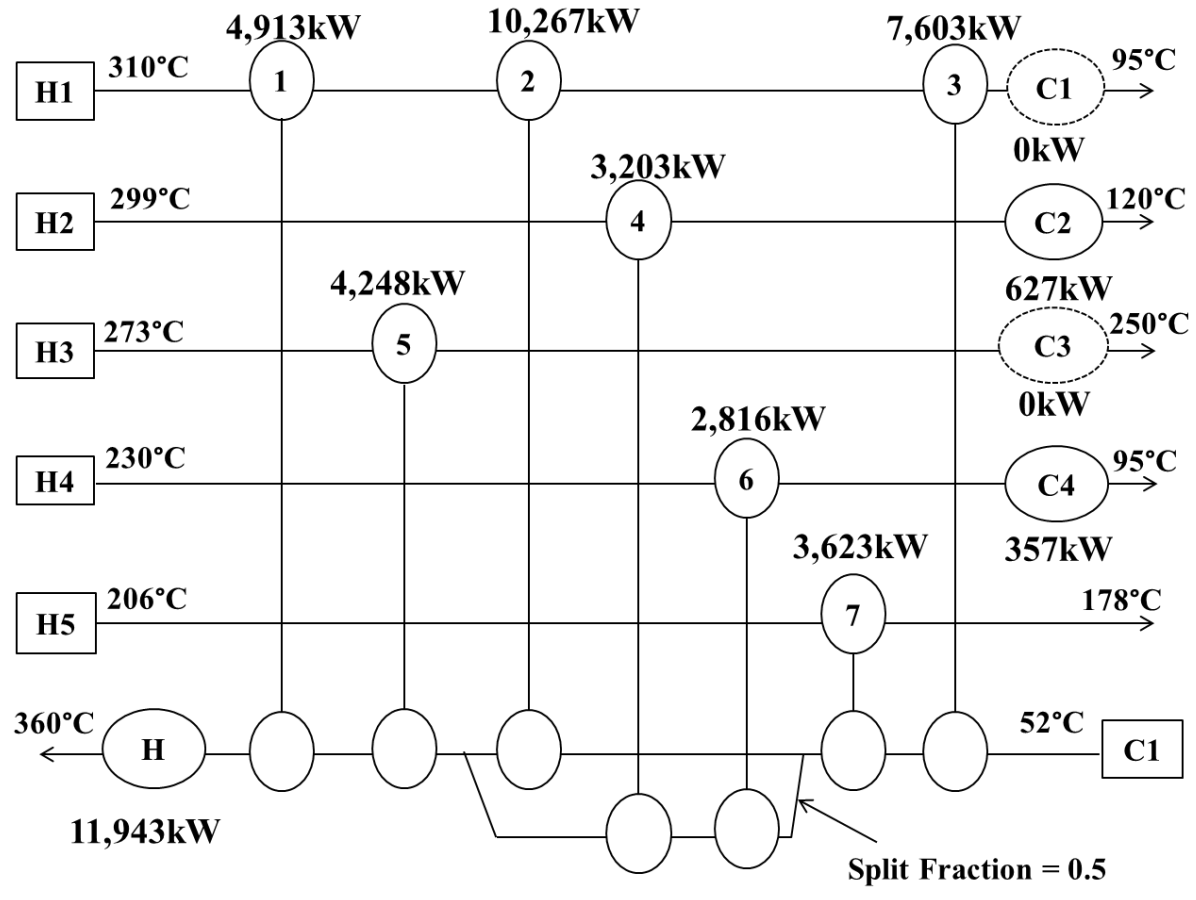

Figure 18: HEN after stream splitting

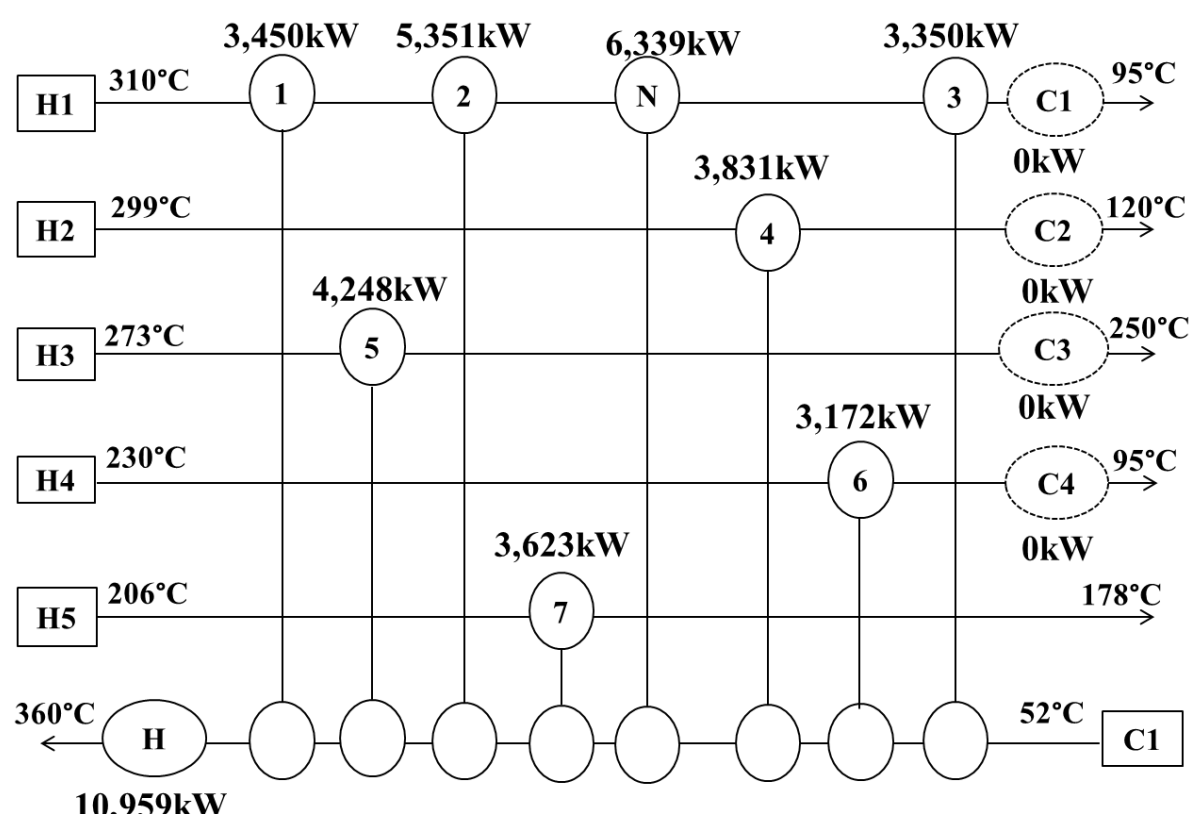

897

898
Figure 19: Retrofitted HEN 
Enhancement

Sequence
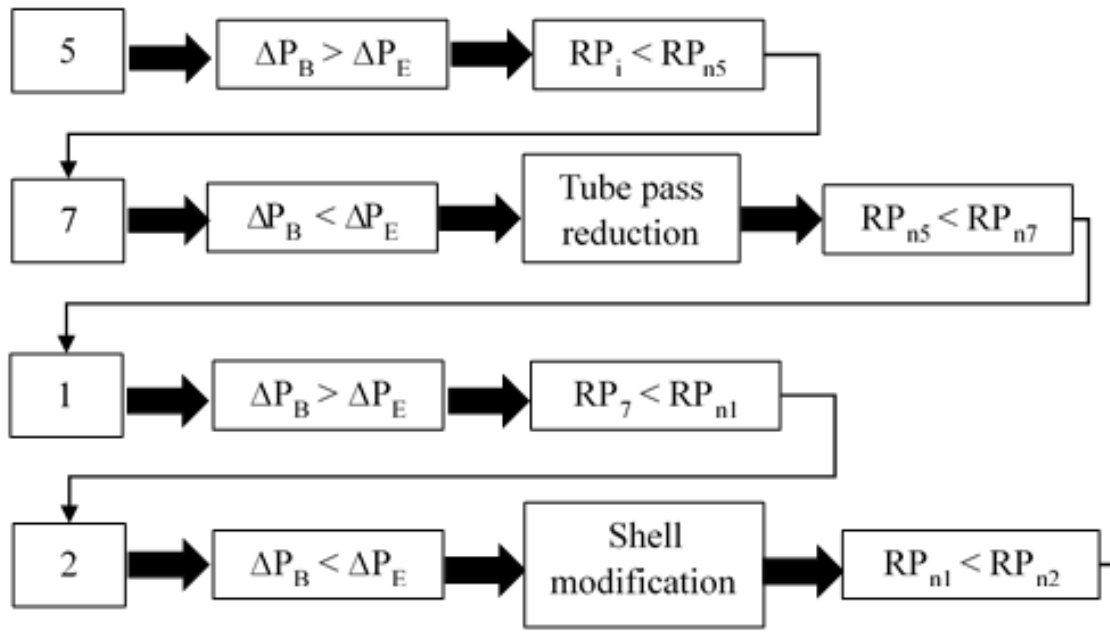

Figure 20: Analysis Sequence

901

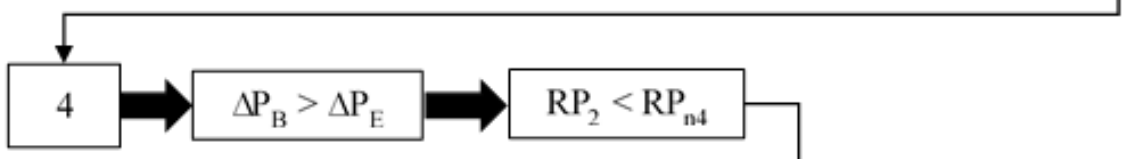

6

\section{$\Delta \mathrm{P}_{\mathrm{B}}>\Delta \mathrm{P}_{\mathrm{E}}$

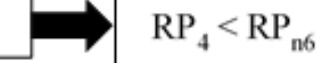

Retrofitted HEN

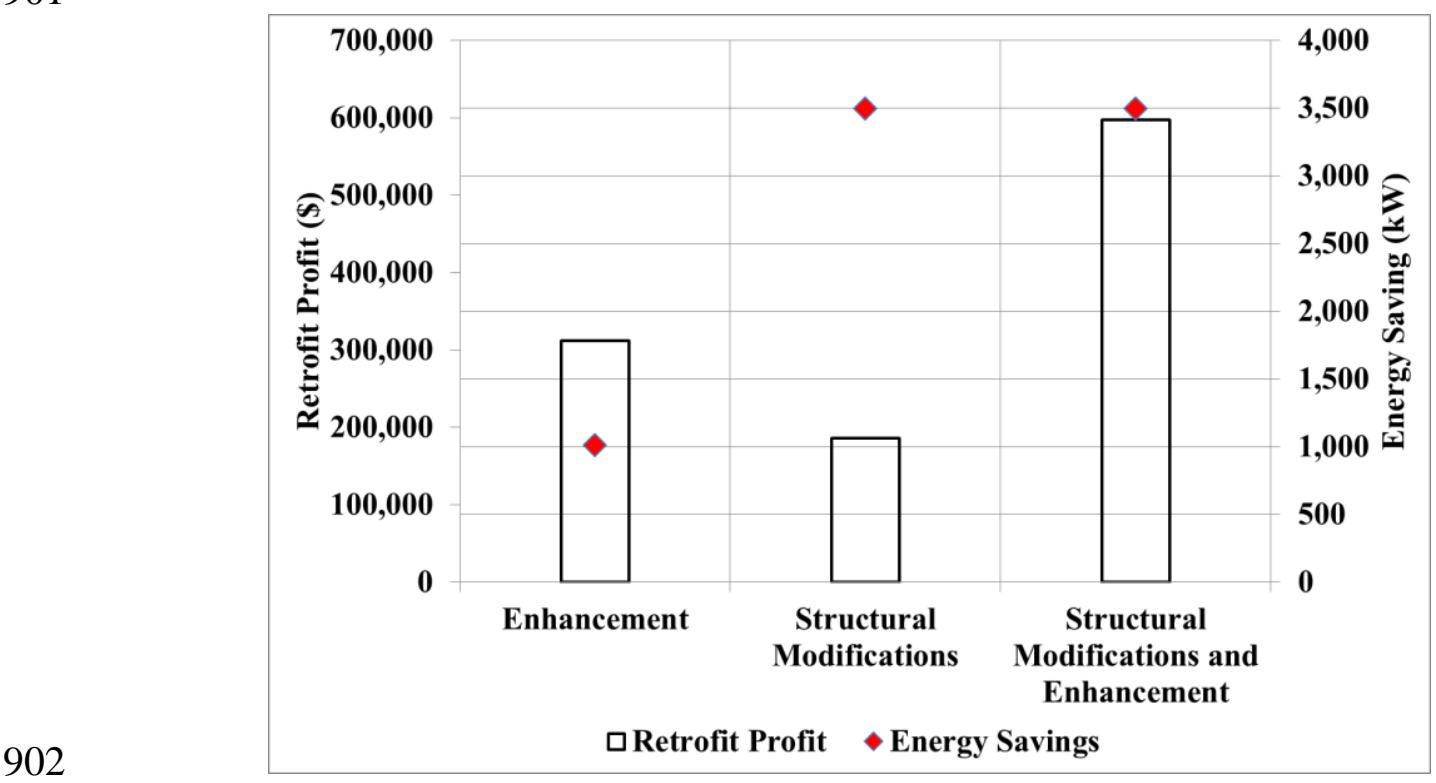

Figure 21: Comparative Analysis 
